\title{
Green Supply Chain Innovation Strategies, considering Government Subsidy and Altruistic Preference
}

\author{
Guangdong Liu $\mathbb{D},{ }^{1,2,3}$ Jinggui Chen, ${ }^{1}$ Ziyang $\mathrm{Li}^{1}{ }^{1}$ and Huagui Zhu $\mathbb{D}^{2}$ \\ ${ }^{1}$ School of Business, Fuyang Normal University, Fuyang, China \\ ${ }^{2}$ School of Management and Engineering, Nanjing University, Nanjing, China \\ ${ }^{3}$ Anhui Provincial Key Laboratory of Regional Logistics Planning and Modern Logistics Engineering, Fuyang, China \\ Correspondence should be addressed to Huagui Zhu; zhg@nju.edu.cn
}

Received 7 October 2021; Revised 18 November 2021; Accepted 6 December 2021; Published 28 February 2022

Academic Editor: Liu Zhi

Copyright (c) 2022 Guangdong Liu et al. This is an open access article distributed under the Creative Commons Attribution License, which permits unrestricted use, distribution, and reproduction in any medium, provided the original work is properly cited.

\begin{abstract}
To study the impact of government subsidies and altruistic preferences on green supply chain innovation, Stackelberg game theory and numerical simulation are used to analyze and verify the optimal decision-making of enterprises under different decisionmaking models. The results show that the two methods of government subsidies can improve product greenness, corporate profits, and overall supply chain performance. While only the unilateral altruistic preference of the manufacturer or retailer can improve product greenness, the profit of the other member, and the overall profit of the green supply chain, doing so will reduce its own profit. When the two members have the same degree of altruistic preference, the retailer's altruistic preference is more conducive to improving product greenness. Increasing government subsidies can strengthen, to a certain extent, the effect of altruistic preference on product greenness, the profit of the other member, and the profit of the green supply chain. However, when the manufacturer implements altruistic preference, if the government subsidy exceeds a certain range, then the increase in the government subsidy will accelerate the decline of the manufacturer's own profit.
\end{abstract}

\section{Introduction}

Currently, the call for environmental protection and green development is growing, which gradually affects the formulation and implementation of major national policies and has an important impact on the planning and production of enterprises [1]. At the same time, in order to respond to corporate social responsibility and meet consumer green demand, more and more companies have taken "Green Sustainable Development" as their development strategic goal, reducing the impact on the environment and conserving resources in production and transportation [2]. For instance, Starbucks announced that it will provide organic straws to replace disposable plastic straws in more than 28,000 stores worldwide [3]. Volvo Corporation announced that it will reduce the use of plastic parts in cars by $30 \%$ by 2025 and replace them with sustainable materials [4]. Many fashion brands such as H\&M, Adidas, Nike, etc., have begun to use recyclable materials for product production in recent years and gradually abandon the use of nonrenewable energy and raw materials [5], and gradually transition to a green and sustainable circular economy.

A series of external pressures simultaneously have also forced the transformation of the traditional supply chain to better adapt to the development of the modern economy simultaneously. In recent years, a green supply chain model that runs through the concept of "Green Sustainable Development" and aims to reduce the negative impact of corporate activities on the environment has developed rapidly and attracted widespread attention from all walks of life [6]. Such as Tesla, Weilai, etc., produce new energy electric vehicles to reduce carbon emissions and reduce the impact on the environment [7]; China's Shanxi and Shaanxi provinces are actively exploring and implementing the conversion of coal into clean energy [8]. In addition, enterprises are an important economic carrier to achieve green 
and sustainable development, and the construction of a corporate green supply chain is an important measure to promote the transformation and development of enterprises and achieve sustainable social and economic development.

However, the construction and implementation of a green supply chain are not easy. This requires companies to invest a lot of funds to update and upgrade equipment, technology R\&D, and talent introduction. The high cost reduces the company's willingness to invest in green technology innovation and production. Moreover, the high prices of green products discourage consumers and further hinder the development of green supply chains [9]. Therefore, in order to encourage enterprises and consumers to transform green production and consumption, many countries have introduced policies such as green subsidies and carbon tax relief to promote the development of green supply chains [10]. For example, the U.S. government implemented a tax deduction of $\$ 2,500$ for electric vehicle purchases in 2009 [11], while China began implementing the "Energy-saving Products Benefiting People Project" in the same year. China also implemented fiscal subsidies and tax reductions for new energy vehicle companies in 2015 [12]. Although government subsidies have played an important role in promoting the development of green supply chains, different subsidy standards, and subsidy targets will produce different green innovation effects. Therefore, studying the impact of government subsidies on green innovation and the green supply chain has important practical significance.

At the same time, government subsidy policies may lead to an unbalanced distribution of benefits among companies, causing disadvantaged companies to take uncooperative or retaliatory measures to punish advantaged companies. For example, while manufacturers may make green product innovations themselves that freely benefit retailers, it is inevitable that manufacturers will perceive this as an imbalance and become unwilling to cooperate. Failure to handle such issues will reduce the efficiency of supply chain operations and even lead to supply chain disruptions [13]. Thus, companies must pay attention not only to their own interests but also to the interests of their partners [14]. In fact, many companies adhere to the concept of mutual benefit and win-win cooperation with business partners for long-term and sustainable business dealings, specifically, supply chain members may not only make decisions based on their own expected profits but also based on their concerns about the interests of their partners, we call it altruistic preference behaviors in the article [15]. For example, Suning comprehensively considers the interests of small merchants when constructing a logistics system, trains their employees for small and medium logistics companies, and adopts a sustainable profit model with these cooperative companies (The interview about Suning, 2010). Apple pays its suppliers in advance to increase the supply of its parts to maintain stable production capacity, and Toyota uses technical training and management support to help its suppliers increase productivity, which can foster long-term partnerships and help achieve common goals. Therefore, it is necessary to study the influence of altruistic preference behavior on the supply chain.
However, few studies have focused on the impact of both government subsidies and altruistic preferences on green supply chain decision-making. Although many scholars believe that government subsidies are an effective way to promote the development of the green supply chain, different government subsidies have different impacts on different altruistic preferences. Related research shows that government subsidies are beneficial to the development and production of green products[16]; however, the existing literature shows that only manufacturers have altruistic preferences and that government subsidies are provided to manufacturers [17-19]. There is a lack of an in-depth study that analyzes the results when manufacturers and consumers are both subsidized and when manufacturers and retailers are both altruistic. Based on the above analysis, this paper poses the following questions:

(1) How do government subsidies and corporate altruistic preferences affect the decision-making along the green supply chain?

(2) Under different altruistic preferences, which strategy is better for the government to subsidize manufacturers and consumers?

(3) Does the enterprise's altruistic preference contribute to the development of the green supply chain? If so, how does this affect the profits of supply chain members?

To answer these questions, this paper develops a twostage green supply chain consisting of a green manufacturer and a retailer and establishes six models of government subsidies delivered to manufacturers and consumers and motivated by self-interest, manufacturer altruism, and retailer altruism in the supply chain. The influences of government subsidies and altruistic behavior on the decisionmaking of supply chain members are studied, the equilibrium results of each model are compared and analyzed, and the validity of the model is tested by numerical analysis.

In summary, the main contributions of this article are: First, we combine altruistic preferences with government subsidies to systematically study the impact of green supply chain innovation and development when manufacturers and retailers are altruistic, which differs from previous work in which only either manufacturers or consumers are individually subsidized, and makes up for the previous lack of green supply chain research. In addition, the influence of altruistic preference behavior on green supply chain decision-making is analyzed theoretically and numerically. Second, unlike the previous literature on altruistic preferences, it takes the weighted average of the company's own profits and the overall profits of the supply chain as a utility function $[20,21]$, but we suppose that the company weighs its own profits and the other's profits, and simultaneously introduces altruistic preference behavior as a ranged variable into it as a utility function. Third, we develop green innovation efficiency to explore its impact on the green supply chain, which has not been considered in prior literature.

The rest of the paper is organized as follows: Section 2 is a literature review; Section 3 is a model description and 
construction; Section 4 is a model solution; Section 5 analyzes the equilibrium results, discusses the different effects of different government subsidies and altruistic preferences on the supply chain, and compares the optimal results; Section 6 is a numerical analysis; Section 7 summarizes the conclusions of the paper and future research work.

\section{Literature Review}

The paper draws upon the literature regarding green supply chains, government subsidies, and altruistic preferences.

2.1. Green Supply Chain. The green supply chain has developed rapidly in the context of global resource conservation and green sustainable development, and many milestones have been achieved in promoting green technological innovation and reducing carbon emissions. Subrata and Mondal [22] analyzed the impact of the credit period on the technological innovation and product pricing of the green supply chain. Wang et al. [23] studied competition between two green supply chains and found that competition for carbon emissions would reduce total optimization cost and carbon emissions. Zhang et al. [24] studied dynamic pricing strategy and greening issues in a two-stage dual-channel green supply chain. Jie et al. [25] studied the impact of manufacturers' fairness concerns and retailers' sales efforts on decision-making in green closedloop supply chains. Jafar et al. [26] studied the coordination problem of green supply chain channels in which market demand is based on a function of the product sales price and green quality. Xia et al. [12] studied the impact of crossshareholding between the manufacturer and retailer under different power structures on green supply chain decisionmaking and technological innovation and realized supply chain coordination through revenue sharing contracts. $\mathrm{Mu}$ et al. [27] constructed a two-stage supply chain for e-commerce sales channels and analyzed the challenges of green technology innovation under different cooperation modes. An et al. [28] studied the impact of green credit financing versus traditional credit financing on green supply chain decision-making and green technological innovation. Wei and Wang [29] analyzed the impact of government intervention policies on technological innovations in carbon emission reduction and concluded that the government and private enterprises should strengthen their cooperation in carbon emission reduction. Wang et al. [9] explored the factors responsible for green product development under different power structures. Liu and Kevin et al. [30] studied the impact of the government's refund of funds policy on the green closed-loop supply chain of waste electronic and electrical equipment recycling. Liu et al. [31] studied how uncertain fairness concerns affect sustainable supply chain decision-making and coordinated them through the Nash bargaining method.

With the change in consumer awareness, market demand for green products has gradually expanded, and enterprises have had to follow this developmental transformation to increase their market sales, scrambling to improve product greenness through technological innovation and so reduce negative effects on the environment. However, implementing green technological innovation will inevitably increase the production cost of enterprises and pose the risk of failure, which may lead to an unwillingness among enterprises to implement it [32]. Therefore, to encourage enterprises to carry out green technological innovation, governments typically adopt subsidy policies.

2.2. Government Subsidy. Various scholars have studied the effect of government subsidies on the green supply chain. Yu et al. [33] explored the optimal government subsidy plan under different circumstances by constructing a two-stage green supply chain model. Meng et al. [34] explored which method the government should adopt in promoting green and sustainable development to establish an effective green subsidy scheme. Fang and Ma [35] believe that the government should provide a subsidy to industries with high carbon emissions to promote carbon emissions reduction. Liu et al. (2020) studied the impact of different fiscal policies and tax subsidies on green technological innovation among different enterprises. Su et al. [36] studied the impact of different forms of subsidies under different power structures on green supply chain pricing decisions. Lin and Jia [37] believe that in terms of renewable energy technology investment, the government should increase subsidies to promote the development of clean energy. Zhang et al. [8] analyzed the ways in which two competing companies make choices in automotive green technology innovation under government subsidies. Bian et al. [38] used the Stackelberg game to study the interaction between the government and enterprises in decision-making on environmental subsidy policies and carbon emission reduction technologies. Meng et al. [39] studied the coordinated pricing of products with government subsidies in a dual-channel green supply chain under the dual preferences of consumers. In a model of one government and two competing companies, Yang et al. [40] explored how to eliminate the prisoner's dilemma between the two companies through government subsidies. Li et al. [41] studied the impact of government subsidies on green innovation in a two-stage supply chain under different power structures. Li et al. [42] analyzed the impact of green technology R\&D subsidies and carbon emission reduction subsidies on two-stage green supply chain decision-making and found that the two subsidy strategies have different effects across industries at different stages. Yu et al. [43] pointed out that government financial subsidies should be used to support the research, development, and deployment of green technologies.

The above-mentioned related literature on government subsidies details the advantages and disadvantages manufacturer subsidies and consumer subsidies possess under different circumstances, but it ignores the behavioral factors of supply chain enterprises. Under normal circumstances, enterprises will pay attention not only to their own development interests but also to the interests of their partners. Thus, altruistic preference behavior has a significant impact on the development of the green supply chain. 
2.3. Altruistic Preference. In fact, many companies may have altruistic preferences to maintain long-term and stable cooperation with supply chain members [21]. Currently, altruistic preference has been extensively studied in supply chain management [44]. Huang et al. [45] explored the influence of the altruistic preference of two cooperating manufacturers and one retailer on supply chain decisionmaking. Fan et al. [20] studied the influence of retailers' altruistic preferences and consumers' green preferences on manufacturers' green R\&D technology investment and supply chain stability. Ma et al. (2019) explored the influence of altruistic preferences on the quality of equipment and the performance of supply chains when studying medical device supply chains. Wang et al. [46] constructed a low-carbon, e-commerce closed-loop supply chain and analyzed the influence of government subsidies and remanufacturers' altruistic preferences on supply chain decision-making. Rong and $\mathrm{Xu}$ [7] found that under those circumstances, the introduction of altruistic preference can be used to alleviate international trade disputes and increase tariffs. Wang et al. [47] studied the influence of altruistic preferences of e-commerce platforms on supply chain decision-making and member-partner cooperation by constructing a platform supply chain for manufacturers and a third-party e-commerce platform. Wang et al. [9] constructed an e-commerce supply chain comprised of a remanufacturer and online recycling platform and examined the impact of reward and punishment mechanisms and altruistic preference on recycling services, product quality improvement, and pricing. The above literature only considers the unilateral altruistic preference behavior of manufacturers, retailers, or third-party platforms and does not comprehensively analyze the two, and most of the literature does not introduce altruistic preference into green supply chain research. To this end, the paper will investigate and analyze manufacturers' and retailers' altruistic preferences in the green supply chain to provide insights for corporate decision-making.

The above-mentioned literature provides important theoretical and managerial insights on the development of green supply chains, but few scholars have conducted comprehensive research and analysis on altruistic preference behavior under concurrent manufacturer and consumer subsidies. This paper uses game theory to study the influence of supply chain members' altruistic preferences and government subsidies on green supply chain innovation and provides a theoretical reference for supply chain decisionmaking.

\section{Model}

This paper develops a two-echelon green supply chain composed of a green manufacturer and a retailer under government subsidies who shows corporate altruistic preferences. The manufacturer, as a leader, develops and produces green products and determines the wholesale price $w$ and product greenness $e$. As a follower, the retailer sells green products to consumers and determines the retail price $p$. The corresponding hypotheses are as follows:
(1) According to Kang et al., [48], assuming a linear demand function, $D=a-b p+r e$ where $a$ is the potential market demand for green products and satisfies $a-b p>0, b$ is the price elasticity of demand, and $r$ is the green preference coefficient of consumers.

(2) According to the literature Swami and Shah [49], the unit fixed production cost of green products is $c$, the $\mathrm{R} \& \mathrm{D}$ cost of green products is $v=k e^{2} / 2,0<e<1$, $v^{\prime}>0, v^{\prime \prime}>0$, and $k$ is the coefficient of green product $\mathrm{R} \& \mathrm{D}$ cost and is infinite.

(3) To encourage enterprises to produce green products and consumers to use green products, the government will give manufacturers and consumers a certain financial subsidy $s$, where $s$ is the subsidy coefficient, When the government subsidizes manufacturers, the subsidy amount is $s k e^{2} / 2$, and when the government subsidizes consumers, the subsidy amount is $p s$.

(4) According to Yang and Tian [50], in this paper, $k / r^{2}$ is called the green innovation cost-value ratio, that is, green innovation efficiency; the lower the ratio, the higher the manufacturer's innovation efficiency.

Based on the above assumptions, this paper develops six decision-making models for government subsidies to manufacturers and consumers under three situations: (1) a completely self-interested preference, (2) a manufacturer's altruistic preference, and (3) a retailer's altruistic preference. The superscripts $n m, n c, m m, m c, r m, r c$ represent six decision-making models, $n, m, r$ on the left represents completely self-interested preference, manufacturer's altruistic preference, and retailer's altruistic preference; $m, c$ on the right represents the manufacturer's subsidy and consumer subsidy, respectively.

When the government subsidizes the manufacturer under a fully self-interested preference, the demand function and the profit function of the manufacturer, retailer, and overall supply chain are as follows:

$$
\begin{aligned}
D & =a-b p+r e, \\
\pi_{m}^{n m} & =(w-c)(a-b p+r e)-\frac{1}{2}(1-s) k e^{2}, \\
\pi_{r}^{n m} & =(p-w)(a-b p+r e), \\
\pi_{s c}^{n m} & =(p-c)(a-b p+r e)-\frac{1}{2}(1-s) k e^{2} .
\end{aligned}
$$

When the government subsidizes consumers under fully self-interested preferences, the demand function and the profit function of the manufacturer, retailer, and overall supply chain are as follows:

$$
\begin{aligned}
D & =a-b p(1-s)+r e, \\
\pi_{m}^{n c} & =(w-c)[a-b p(1-s)+r e]-\frac{1}{2} k e^{2},
\end{aligned}
$$




$$
\begin{aligned}
& \pi_{r}^{n c}=(p-w)[a-b p(1-s)+r e], \\
& \pi_{s c}^{n c}=(p-c)[a-b p(1-s)+r e]-\frac{1}{2} k e^{2} .
\end{aligned}
$$

When the manufacturer and retailer have altruistic preference behavior, according to the literature [2], $\lambda_{i}$ $\left(0<\lambda_{i}<1, i=m, r\right)$ is used to represent the altruistic preference coefficient of the manufacturer and retailer. The larger the value of $\lambda$, the higher the altruistic preference of the manufacturer and retailer, so the utility functions of the manufacturer and retailer are as follows:

$$
\begin{gathered}
U_{m}=\pi_{m}+\lambda_{m} \pi_{r}, \\
U_{r}=\pi_{r}+\lambda_{r} \pi_{m} .
\end{gathered}
$$

\section{Model Solution}

4.1. Decision-Making in the Green Supply Chain under Completely Self-Interested Preference. A completely self-interested preference means that enterprises only consider their own interests and take the maximization of their own interests as their decision-making goal. This paper considers two situations in which the government subsidizes manufacturers and consumers.

4.1.1. Model of the Subsidizing Manufacturer under Fully SelfInterested Preference $(\mathrm{nm})$. The optimal values are obtained by reverse induction in the $n m$ model according to formulas (1)-(4). Proposition 1 can be obtained by reverse induction.

Proposition 1. When the government subsidizes the manufacturer under a completely self-interested preference, the retail price, wholesale price, and product greenness are obtained:

$$
\begin{aligned}
p^{n m^{*}} & =\frac{k(3 a+b c)(1-s)-c r^{2}}{4 b k(1-s)-r^{2}}, \\
w^{n m^{*}} & =\frac{2 k(a+b c)(1-s)-c r^{2}}{4 b k(1-s)-r^{2}}, \\
e^{n m^{*}} & =\frac{(a-b c) r}{4 b k(1-s)-r^{2}} .
\end{aligned}
$$

The proof is displayed in Appendix A.

So the profits of the supply chain can be obtained:

$$
\begin{aligned}
& \pi_{m}^{n m^{*}}=\frac{k(a-b c)^{2}(1-s)}{2\left[4 b k(1-s)-r^{2}\right]}, \\
& \pi_{r}^{n m^{*}}=\frac{b k^{2}(a-b c)^{2}(1-s)^{2}}{\left[4 b k(1-s)-r^{2}\right]^{2}}, \\
& \pi_{s c}^{n m^{*}}=\frac{k(a-b c)^{2}(1-s)\left[6 b k(1-s)-r^{2}\right]}{2\left[4 b k(1-s)-r^{2}\right]^{2}} .
\end{aligned}
$$

4.1.2. Model of Subsidizing Consumers under Completely Self-Interested Preference (nc). The optimal values are obtained by reverse induction in $n c$ according to formulas (5)-(8). Proposition 2 can be obtained by reverse induction.

Proposition 2. When the government subsidizes consumers under a completely self-interested preference, the retail price, wholesale price, and product greenness are obtained:

$$
\begin{aligned}
p^{n c^{*}} & =\frac{3 a k+b c k(1-s)-c r^{2}}{4 b k(1-s)-r^{2}}, \\
w^{n c^{*}} & =\frac{2 a k+2 b c k(1-s)-c r^{2}}{4 b k(1-s)-r^{2}}, \\
e^{n c^{*}} & =\frac{[a-b c(1-s)] r}{4 b k(1-s)-r^{2}} .
\end{aligned}
$$

The proof is displayed in Appendix B.

Therefore, the optimal profits of the supply chain can be obtained as follows:

$$
\begin{aligned}
& \pi_{m}^{n c *}=\frac{k[a-b c(1-s)]^{2}}{2\left[4 b k(1-s)-r^{2}\right]}, \\
& \pi_{r}^{n c *}=\frac{b k^{2}(1-s)[a-b c(1-s)]^{2}}{\left[4 b k(1-s)-r^{2}\right]^{2}}, \\
& \pi_{s c}^{n c *}=\frac{k[a-b c(1-s)]^{2}\left[6 b k(1-s)-r^{2}\right]}{2\left[4 b k(1-s)-r^{2}\right]^{2}} .
\end{aligned}
$$

\subsection{Decision-Making in the Green Supply Chain under Altruistic Preference of Manufacturers}

4.2.1. Model of Subsidizing Manufacturer under Altruistic Preference of the Manufacturer ( $\mathrm{mm}$ ). Taking formulas (2) and (3) into formula (9), the manufacturer's utility function can be obtained as follows:

$$
\begin{aligned}
U_{m}^{m m}= & (w-c)(a-b p+r e) \\
& -\frac{1}{2}(1-s) k e^{2}+\lambda_{m}[(p-w)(a-b p+r e)] .
\end{aligned}
$$

Proposition 3 can be obtained by reverse induction:

Proposition 3. When the manufacturer has an altruistic preference and the government subsidizes the manufacturer, the optimal values of the manufacturer and retailer are as follows: 


$$
\begin{aligned}
p^{m m^{*}} & =\frac{k(1-s)\left[a\left(3-2 \lambda_{m}\right)+b c\right]-c r^{2}}{2 b k\left(2-\lambda_{m}\right)(1-s)-r^{2}}, \\
w^{m m^{*}} & =\frac{2 k(1-s)\left[a\left(1-\lambda_{m}\right)+b c\right]-c r^{2}}{2 b k\left(2-\lambda_{m}\right)(1-s)-r^{2}}, \\
e^{m m^{*}} & =\frac{(a-b c) r}{2 b k\left(2-\lambda_{m}\right)(1-s)-r^{2}}
\end{aligned}
$$

The proof is displayed in Appendix C.

Furthermore, the utility of the manufacturer and the overall profits of the manufacturer, retailer, and supply chain can be obtained as follows:

$$
\begin{aligned}
\pi_{m}^{m m^{*}} & =\frac{k(a-b c)^{2}(1-s)\left[4 b k\left(1-\lambda_{m}\right)(1-s)-r^{2}\right]}{2\left[2 b k\left(2-\lambda_{m}\right)(1-s)-r^{2}\right]^{2}}, \\
\pi_{r}^{m m^{*}} & =\frac{b k^{2}(a-b c)^{2}(1-s)^{2}}{\left[2 b k\left(2-\lambda_{m}\right)(1-s)-r^{2}\right]^{2}}, \\
\pi_{s c}^{m m^{*}} & =\frac{k(a-b c)^{2}(1-s)\left[2 b k\left(3-2 \lambda_{m}\right)(1-s)-r^{2}\right]}{2\left[2 b k\left(2-\lambda_{m}\right)(1-s)-r^{2}\right]^{2}}, \\
U_{m}^{m m^{*}} & =\frac{k(a-b c)^{2}(1-s)}{2\left[2 b k\left(2-\lambda_{m}\right)(1-s)-r^{2}\right]} .
\end{aligned}
$$

4.2.2. Model of Subsidizing Consumers under Altruistic Preference of the Manufacturer ( $m c)$. Taking formula (6) and (7) into (9), the manufacturer's utility function can be obtained:

$$
\begin{aligned}
U_{m}^{m c}= & (w-c)[a-b p(1-s)+r e] \\
& -\frac{1}{2} k e^{2}+\lambda_{m}[(p-w)(a-b p(1-s)+r e)] .
\end{aligned}
$$

Proposition 4 can be obtained by reverse induction.

Proposition 4. When manufacturers have altruistic preferences and the government subsidizes consumers, the optimal decision variables of manufacturers and retailers are as follows:

$$
\begin{aligned}
p^{m c^{*}} & =\frac{a k\left(3-2 \lambda_{m}\right)+b c k(1-s)-c r^{2}}{2 b k(1-s)\left(2-\lambda_{m}\right)-r^{2}} \\
w^{m c^{*}} & =\frac{2 a k\left(1-\lambda_{m}\right)+2 b c k(1-s)-c r^{2}}{2 b k(1-s)\left(2-\lambda_{m}\right)-r^{2}} \\
e^{m c^{*}} & =\frac{[a-b c(1-s)] r}{2 b k(1-s)\left(2-\lambda_{m}\right)-r^{2}}
\end{aligned}
$$

The proof is displayed in Appendix D.
Then, the profits of the manufacturer, retailer, and supply chain, and the utility of the manufacturer can be obtained:

$$
\begin{aligned}
\pi_{m}^{m c^{*}} & =\frac{k[a-b c(1-s)]^{2}\left[4 b k(1-s)\left(1-\lambda_{m}\right)-r^{2}\right]}{2\left[2 b k(1-s)\left(2-\lambda_{m}\right)-r^{2}\right]^{2}}, \\
\pi_{r}^{m c^{*}} & =\frac{b k^{2}(1-s)[a-b c(1-s)]^{2}}{\left[2 b k(1-s)\left(2-\lambda_{m}\right)-r^{2}\right]^{2}}, \\
\pi_{s c}^{m c^{*}} & =\frac{k[a-b c(1-s)]^{2}\left[2 b k(1-s)\left(3-2 \lambda_{m}\right)-r^{2}\right]}{2\left[2 b k(1-s)\left(2-\lambda_{m}\right)-r^{2}\right]^{2}}, \\
U_{m}^{m c^{*}} & =\frac{k[a-b c(1-s)]^{2}}{2\left[2 b k(1-s)\left(2-\lambda_{m}\right)-r^{2}\right]} .
\end{aligned}
$$

\subsection{Decision-Making in the Green Supply Chain under Altruistic Preference of Retailers}

4.3.1. Model of Subsidizing Manufacturer under Altruistic Preference of the Retailer ( $\mathrm{rm}$ ). Taking Formulas (2) and (3) into formula (10), the retailer's utility can be obtained:

$$
\begin{aligned}
U_{r}^{r m}= & (p-w)(a-b p+r e) \\
& +\lambda_{r}\left[(w-c)(a-b p+r e)-\frac{1}{2}(1-s) k e^{2}\right] .
\end{aligned}
$$

Proposition 5 can be obtained by reverse induction.

Proposition 5. When the retailer has an altruistic preference, and the government subsidizes manufacturers, the optimal values of the supply chain are obtained:

$$
\begin{aligned}
p^{r m^{*}} & =\frac{\left(1-\lambda_{r}\right)(1-s)(3 a+b c) k-c r^{2}}{4 b k\left(1-\lambda_{r}\right)(1-s)-r^{2}}, \\
w^{r m^{*}} & =\frac{2 k(1-s)\left[a+b c\left(1-2 \lambda_{r}\right)\right]-c r^{2}}{4 b k\left(1-\lambda_{r}\right)(1-s)-r^{2}}, \\
e^{r m^{*}} & =\frac{(a-b c) r}{4 b k\left(1-\lambda_{r}\right)(1-s)-r^{2}} .
\end{aligned}
$$

The proof is displayed in Appendix E.

Then, the profits of the manufacturer, retailer, and supply chain, and the utility of the retailer can be obtained:

$$
\begin{aligned}
\pi_{m}^{r m^{*}} & =\frac{k(a-b c)^{2}(1-s)}{2\left[4 b k\left(1-\lambda_{r}\right)(1-s)-r^{2}\right]}, \\
U_{r}^{r m^{*}} & =\frac{k(a-b c)^{2}(1-s)\left[2 b k(1-s)\left(1-\lambda_{r}\right)^{2}-\lambda_{r} r^{2}\right]}{2\left[4 b k\left(1-\lambda_{r}\right)(1-s)-r^{2}\right]^{2}}, \\
\pi_{r}^{r m^{*}} & =\frac{b k^{2}(a-b c)^{2}(1-s)^{2}\left(1-3 \lambda_{r}\right)\left(1-\lambda_{r}\right)}{\left[4 b k\left(1-\lambda_{r}\right)(1-s)-r^{2}\right]^{2}}
\end{aligned}
$$




$$
\pi_{s c}^{r m^{*}}=\frac{k(a-b c)^{2}(1-s)\left[6 b k\left(1-\lambda_{r}\right)^{2}(1-s)-r^{2}\right]}{2\left[4 b k\left(1-\lambda_{r}\right)(1-s)-r^{2}\right]^{2}} .
$$

4.3.2. Model of Subsidizing Consumers under the Altruistic Preferences of Retailers ( $r c$ ). Taking Formulas (6) and (7) into formula (10), the manufacturer's utility can be obtained:

$$
\begin{aligned}
U_{r}^{r c}= & (p-w)[a-b p(1-s)+r e] \\
& +\lambda_{r}\left[(w-c)(a-b p+r e)-\frac{1}{2} k e^{2}\right] .
\end{aligned}
$$

Proposition 6 can be obtained by reverse induction.

Proposition 6. When the retailer has an altruistic preference, and the government subsidizes consumers, the optimal values of the supply chain are as follows:

$$
\begin{aligned}
p^{r c *} & =\frac{3 a k\left(1-\lambda_{r}\right)+b c k\left(1-\lambda_{r}\right)(1-s)-c r^{2}}{4 b k(1-s)\left(1-\lambda_{r}\right)-r^{2}}, \\
w^{r c *} & =\frac{2 k\left[a+b c(1-s)\left(1-2 \lambda_{r}\right)\right]-c r^{2}}{4 b k(1-s)\left(1-\lambda_{r}\right)-r^{2}}, \\
e^{r c *} & =\frac{[a-b c(1-s)] r}{4 b k(1-s)\left(1-\lambda_{r}\right)-r^{2}} .
\end{aligned}
$$

The proof is displayed in Appendix F.

Then, the profits of the manufacturer, retailer and supply chain, and the utility of the retailer can be obtained:

$$
\begin{aligned}
\pi_{m}^{r c *} & =\frac{k[a-b c(1-s)]^{2}}{2\left[4 b k(1-s)\left(1-\lambda_{r}\right)-r^{2}\right]}, \\
\pi_{r}^{r c *} & =\frac{b k^{2}[a-b c(1-s)]^{2}\left(1-3 \lambda_{r}\right)\left(1-\lambda_{r}\right)(1-s)}{\left[4 b k(1-s)\left(1-\lambda_{r}\right)-r^{2}\right]^{2}}, \\
\pi_{s c}^{r c *} & =\frac{k[a-b c(1-s)]^{2}\left[6 b k(1-s)\left(1-\lambda_{r}\right)^{2}-r^{2}\right]}{2\left[4 b k(1-s)\left(1-\lambda_{r}\right)-r^{2}\right]^{2}}, \\
U_{r}^{r c *} & =\frac{k[a-b c(1-s)]^{2}\left[2 b k(1-s)\left(1-\lambda_{r}\right)^{2}-\lambda_{r} r^{2}\right]}{2\left[4 b k(1-s)\left(1-\lambda_{r}\right)-r^{2}\right]^{2}} .
\end{aligned}
$$

\section{Comparative Analysis}

To ensure that the optimal values of the supply chain are scientific and significant in the paper, they must meet $k / r^{2}>1 / 4 b(1-s)$. For ease of expression, let $A=1 / 4 b(1-s)$. When the retailer has an altruistic preference, to satisfy the condition that the retailer's profit is positive, the retailer's altruistic coefficient must satisfy $0<\lambda_{r}<1 / 3$. Then, suppose that $\lambda_{m}=\lambda_{r}$ for comparison in different models in the section. In addition, when the government subsidizes consumers, the results are too complicated, so they will be analyzed in the numerical analysis section.

\section{Corollary 1}

(1) $\partial e^{i *} / \partial s>0 \quad(i=n m, m m, r m, n c, m c, r c) ; \quad \partial e^{x *} / \partial \lambda_{m}$ $>0, \quad \partial^{2} e^{x *} / \partial \lambda_{m} \partial s>0 \quad(x=m m, m c) ; \quad \partial e^{y *} / \partial \lambda_{r}>0$, $\partial^{2} e^{y *} / \partial \lambda_{r} \partial s>0(y=r m, r c)$.

(2) $e^{r m^{*}}>e^{m m^{*}}>e^{n m^{*}}, e^{r c *}>e^{m c^{*}}>e^{n c *}$.

The proof is displayed in Appendix G.

Regardless of whether the government subsidizes the manufacturer or the consumer when the manufacturer and retailer demonstrate altruistic preference, product greenness improves as government subsidies increase. Product greenness is highest when the retailer is altruistic and lowest when the supply chain is completely self-interested. This is because the government subsidizes manufacturers to reduce their green technology $\mathrm{R} \& \mathrm{D}$ cost, the manufacturer prefers to produce greener products, and when the government subsidizes consumers, it stimulates market demand for green products. The altruistic preference of the manufacturer will increase retailer profit by improving product greenness to stimulate market demand. Similarly, the retailer's altruistic preference encourages the retailer to accept a higher wholesale price from the manufacturer to motivate the manufacturer to produce green products. In addition, government subsidies and retailers' altruistic preferences jointly encourage manufacturers to improve product greenness, resulting in the highest level of greenness. However, under the complete selfinterest preference, product greenness is reduced due to the double marginal effect, resulting in the lowest greenness compared to that under the retailer's altruistic preference and manufacturer's altruistic preference.

\section{Corollary 2}

(1) $\partial w^{i *} / \partial s>0, \partial p^{i *} / \partial s>0(i=n m, m m, r m, n c, m c, r c)$; $\partial w^{y *} / \partial \lambda_{r}>0 ; \quad \partial p^{y *} / \partial \lambda_{r}>0 \quad(y=r m, r c) ; \quad$ when $A<k / r^{2}<1 / 2 b(1-s), \partial w^{x *} / \partial \lambda_{m}>0, \partial p^{x *} / \partial \lambda_{m}>0$; when $k / r^{2}>1 / b(1-s), \quad \partial w^{x *} / \partial \lambda_{m}<0 \quad$ and $\partial p^{x *} / \partial \lambda_{m}<0(x=m m, m c)$

(3) when $A<k / r^{2}<1 / 2 b(1-s), \quad w^{r m^{*}}>w^{m m^{*}}>w^{n m^{*}}$, $p^{r m^{*}}>p^{m m^{*}}>p^{n m^{*}} ; \quad w^{r c *}>w^{m c^{*}}>w^{n c *}, \quad p^{r c *}>$ $p^{m c^{*}}>p^{n c *} ;$ when $k / r^{2}>1 / b(1-s), w^{r m^{*}}>w^{n m^{*}}>$ $w^{m m^{*}}, p^{r m^{*}}>p^{n m^{*}}>p^{m m^{*}}, w^{r c *}>w^{n c *}>w^{m c^{*}}$, and $p^{r c *}>p^{n c *}>p^{m c^{*}}$

The proof is displayed in Appendix $H$.

Under the retailer's altruistic preference, when the government subsidizes either the manufacturer or consumers, the wholesale price and retail price increase, respectively, with increasing levels of subsidies but the relationship with the manufacturer's altruistic preference is affected by the manufacturer's green innovation efficiency. First, Corollary 1 shows that product greenness can be improved regardless of whether the government subsidizes the manufacturer or consumers. Although government subsidies can reduce the green technology R\&D cost of the manufacturer to some extent, most of the R\&D cost is still borne solely by the manufacturer. When 
the government subsidizes consumers instead of reducing the cost of green technology R\&D for manufacturers, then the cost to manufacturers may, in fact, increase. Thus, the manufacturer's costs are different under different subsidies and the manufacturer can increase the wholesale price to offset the increased cost of green $\mathrm{R} \& \mathrm{D}$, which may result in a high retail price. Second, the retailer's altruistic preference will help further the manufacturer's interests and lead the retailer to accept a higher wholesale price, thereby increasing the retail price. Third, when the efficiency of green innovation is low, the cost of increasing unit greenness is higher. At the same time, the manufacturer is driven by altruistic preferences to increase product greenness in order to increase market demand and further the interests of the retailer. An increase in greenness implies an increase in the cost to the manufacturer, who then must increase the wholesale price to maintain their profit, thereby raising the retail price. When the efficiency of green innovation is high, the unit cost of increasing product greenness is low, and the manufacturer's altruistic preference will reduce the wholesale price to increase the profit of the retailer, so the retail price will also decrease to some extent.

The analysis above shows that government subsidies and retailers' altruism preferences will increase both wholesale and retail prices, which are highest under different subsidies and preferences. When the efficiency of green innovation is low, the manufacturer's altruistic preference will also increase the wholesale and retail price, which will be greater than the price under a completely self-interested preference. When the efficiency of green innovation is high, the manufacturer's altruistic preference will reduce the wholesale and retail price, resulting in a lower price than that under a completely self-interested preference.

\section{Corollary 3}

(1) $\partial \pi_{m}^{i *} / \partial s>0 \quad(i=n m, r m) ; \partial \pi_{m}^{x *} / \partial \lambda_{m}<0, \partial \pi_{m}^{y *} / \partial \lambda_{r}$ $>0(x=m m, m c, y=r m, r c)$

When $0<\lambda_{m}<2 / 3$ and $k / r^{2}>1 / 2 b\left(2-3 \lambda_{m}\right)(1-s)$, $\partial \pi_{m}^{m m^{*}} / \partial s>0$; when $0<\lambda_{m}<2 / 3$ and $A<k / r^{2}$ $<1 / 2 b\left(2-3 \lambda_{m}\right)(1-s)$ or when $2 / 3<\lambda_{m}<1$, $\partial \pi_{m}^{m m^{*}} / \partial s<0$

(2) $\pi_{m}^{r m}>\pi_{m}^{n m}>\pi_{m}^{m m} ; \pi_{m}^{r c}>\pi_{m}^{n c}>\pi_{m}^{m c}$

The proof is displayed in Appendix I.

When the government subsidizes the manufacturer or consumers, the profit of the manufacturer increases with the increase of government subsidy and retailer's altruistic preference but decreases with the increase of his own altruistic preference. First, the government subsidizes the manufacturer to reduce green technology $\mathrm{R} \& \mathrm{D}$ costs and increase profit margin. Second, the retailer's altruistic preference will benefit the manufacturer by increasing the manufacturer's profit. Therefore, the manufacturer's profit is highest under government subsidies and the retailer's altruistic preference. Conversely, the manufacturer's altruistic preference can increase the profit of the retailer but at the expense of his own profit. Third, in the $\mathrm{mm}$ model, when the manufacturer's altruistic preference is low, the manufacturer's green efficiency is high and other parameters are unchanged, the manufacturer's profit increases as government subsidies increase. When green innovation efficiency is low, the opposite is true. When the manufacturer's altruistic preference is high, the profit of the manufacturer will decrease because the benefit to the retailer cannot be offset by a rise in government subsidies.

Combined with the above analysis, it can be shown that the manufacturer's profit is highest when the retailer is altruistic and lowest when the manufacturer is altruistic under government subsidies. The reasons are as follows: First, the manufacturer's profit is increased by the benefit of the retailer when the retailer is altruistic under government subsidy, so the manufacturer's profit is highest at this time. Second, when the manufacturer is altruistic, it will transfer part of its profit to the retailer and will bear more of the green $\mathrm{R} \& \mathrm{D}$ cost due to the increase in greenness, so its profit is lowest in this situation.

\section{Corollary 4}

(1) $\partial \pi_{r}^{i *} / \partial s>0(i=n m, m m, r m) ; \partial \pi_{r}^{x *} / \partial \lambda_{m}>0, \partial \pi_{r}{ }^{y *} /$ $\partial \lambda_{r}<0(x=m m, m c, y=r m, r c)$

(2) When $k / r^{2}>3 / 4 b(1-s)$ or when $A<k / r^{2}<3$ / $4 b(1-s)$ and $1>\lambda_{r}>8 b k(1-s)\left[3 r^{2}-4 b k(1-s)\right]-$ $4 r^{4} / 8 b k(1-s)\left[3 r^{2}-4 b k(1-s)\right]-3 r^{4}, \pi_{r}^{m m}>\pi_{r}^{n m}>$ $\pi_{r}^{r m}, \pi_{r}^{m c}>\pi_{r}^{n c}>\pi_{r}^{r c}$; when $A<k / r^{2}<3 / 4 b(1-s)$ and $0<\lambda_{r}<8 b k(1-s)\left[3 r^{2}-4 b k(1-s)\right]-4 r^{4} / 8 b k(1-s)$ $\left[3 r^{2}-4 b k(1-s)\right]-3 r^{4}, \pi_{r}^{m m}>\pi_{r}^{r m}>\pi_{r}^{n m}, \pi_{r}^{m c}>\pi_{r}^{r c}$ $>\pi_{r}^{n c}$

The proof is displayed in Appendix J.

When the government subsidizes the manufacturer or consumers, the retailer's profit increases with the increase of government subsidy and the manufacturer's altruistic preference, but it decreases with the increase of its own altruistic preference. This is because retailer profit can be significantly improved by the increase in product greenness and market demand, and the manufacturer's altruistic preference will motivate the retailer to increase its profit. Similarly, the retailer's altruistic preference will benefit the manufacturer and lead to a decrease in its profit.

Corollary 5. The manufacturer's altruistic preference will reduce the wholesale price and benefit the retailer; regardless of whether the government has subsidized the manufacturer or the consumer, the retailer's profit will be the largest. When the efficiency of green innovation is high due to the retailer's altruistic preference, the retailer will benefit the manufacturer at a reduction of its own profit. When completely self-interested, the retailer will maximize its own interests, so its profit is higher than that when it is altruistic. In addition, when the manufacturer's green innovation efficiency is low and the retailer's altruistic preference is high, then the retailer will benefit the manufacturer, leading to lower profit than when it is completely self-interested. When the retailer's altruistic preference is low, the opposite is true. 


\section{Corollary 6}

(1) $\partial \pi_{s c}^{x *} / \partial s>0(x=n m, m m, r m), \partial \pi_{s c}^{i *} / \partial \lambda_{j}>0$ (i=mm, $m c, r m, r c, j=m, r)$

(2) $\pi_{s c}^{m m}>\pi_{s c}^{r m}>\pi_{s c}^{n m} ; \pi_{s c}^{m c}>\pi_{s c}^{r c}>\pi_{s c}^{n c}$

The proof is displayed in Appendix K.

The profit of the supply chain increases with increasing government subsidies and altruistic preferences. First, from Corollary 3 (1) and Corollary 4 (1), we see that government subsidies will increase the profits of the manufacturer and retailer, which can increase the total profit of the supply chain. Second, although the altruistic preferences of the manufacturer and retailer are detrimental to their own interests, from a longterm perspective, the increase in the overall profit of the supply chain can offset the losses caused by altruistic preferences.

Whether the government subsidizes the manufacturer or the consumer, the profit of the supply chain is highest when the manufacturer is altruistic and lowest when it is completely self-interested. This shows that altruistic preferences under government subsidies are conducive to the development of the supply chain to a certain extent. This will aggravate the competition between supply chain members under complete self-interest, leading to a double marginal effect. Therefore, government subsidies and altruistic preferences have a positive impact on supply chain operations.

Corollary 7 According to the optimal equilibrium results under two subsidy strategies, the following relationships can be obtained:

(1) Under completely self-interested: $p^{n m^{*}}<p^{n c *}$, $w^{n m^{*}}<w^{n c *}, \quad e^{n m^{*}}<e^{n c *}, \pi_{m}^{n m^{*}}<\pi_{m}^{n c *}, \pi_{r}^{n m^{*}}<\pi_{r}^{n c *}$, $\pi_{s c}^{n m^{*}}<\pi_{s c}^{n c *}$

(2) Under manufacturer's altruistic preference: $p^{m m^{*}}<p^{m c^{*}}, w^{m m^{*}}<w^{m c^{*}}, e^{m m^{*}}<e^{m c^{*}}, \pi_{m}^{m m^{*}}<\pi_{m}^{m c^{*}}$, $\pi_{r}^{m m^{*}}<\pi_{r}^{m c^{*}}, \pi_{s c}^{m m^{*}}<\pi_{s c}^{m c^{*}}$

(3) Under the retailer's altruistic preference: $p^{r m^{*}}<p^{r c *}$, $w^{r m^{*}}<w^{r c *}, \quad e^{r m^{*}}<e^{r c *}, \quad \pi_{m}^{r m^{*}}<\pi_{m}^{r c *}, \quad \pi_{r}^{r m^{*}}<\pi_{r}^{r c *}$, $\pi_{s c}^{r m^{*}}<\pi_{s c}^{r c *}$

The proof is displayed in Appendix L.

Corollary 8. Consumer subsidies are better than manufacturer subsidies regardless of altruistic preference. The reasons are as follows: First, the impact of consumer subsidies on product greenness and market demand is active, and make-toorder production can achieve Pareto equilibrium and reduce market risk and inventory. Second, although manufacturer subsidies can also stimulate product greenness and market demand, retailers and manufacturers lack sufficient understanding of the green product market under asymmetric information, which leads to blind investment and fight risk ability. Third, although the manufacturer and retailer are not completely rational, they will prioritize their own profits above all else. Therefore, rent-seeking behavior will inevitably occur, leading to a waste of resources and a disrupting market order. Therefore, the influences of different subsidy strategies should be considered when formulating government subsidy policies.

\section{Numerical Analysis}

In this section, the numerical simulation will be carried out, letting $a=500, b=1, c=20, k=100, r=2, s=(0,1)$, $\lambda_{m}=(0,1), \lambda_{r}=(0,1 / 3)$ :

(1) Figure 1 shows that regardless of whether the government subsidizes the manufacturer or the consumer, product greenness increases under altruistic preference as government subsidies increase. Compared with manufacturer subsidies and manufacturers' altruistic preferences, consumer subsidies and retailers' altruistic preferences can improve product greenness. In addition, increased government subsidies and altruistic preferences can strengthen the improvement of product greenness, thereby improving green innovation capability and reducing carbon emissions. This is consistent with the conclusion of Corollary 1. Therefore, the government should provide subsidies to consumers to avoid the occurrence of "fraud compensation," which is more conducive to product greenness.

(2) Figures 2 and 3 show that when the government subsidizes the manufacturer or consumers, wholesale and retail prices increase as government subsidies increase. Government subsidies directly or indirectly encourage the manufacturer to increase product greenness, which also means that R\&D costs will increase for the manufacturer, and the wholesale price will be increased to maintain operating profit, which in turn will lead to an increase in retail price. Thus, as the altruistic preference of the manufacturer or retailer increases, wholesale and retail prices decrease and vice versa. Wholesale and retail prices under consumer subsidies are higher than those under manufacturer subsidies, consistent with Corollary 2. Manufacturer subsidies cause wholesale and retail prices to rise, indicating that manufacturer subsidies do not enable consumers to obtain price concessions. Therefore, the government should favor consumer subsidies under the same circumstances.

(3) Figure 4 shows that under government subsidies, the profits of the manufacturer increase with the increase in the retailer's altruistic preference but decrease with the increase of the self-altruistic preference, and $\pi_{m}^{m m}<\pi_{m}^{n m}<\pi_{m}^{r m}, \pi_{m}^{m c}<\pi_{m}^{n c}<\pi_{m}^{r c}$, verifying the conclusion of Corollary 3. Although government subsidies are generally conducive to raising the manufacturer's profits, in the $\mathrm{mm}$ and $\mathrm{mc}$ models, government subsidies can only increase the profit of the manufacturer within a certain range, beyond which they accelerate their decline. Thus, it is not necessarily the case that the higher the government subsidies, the better. Therefore, it is better to promote green innovation by only making full use of the incentive role of government subsidies. 


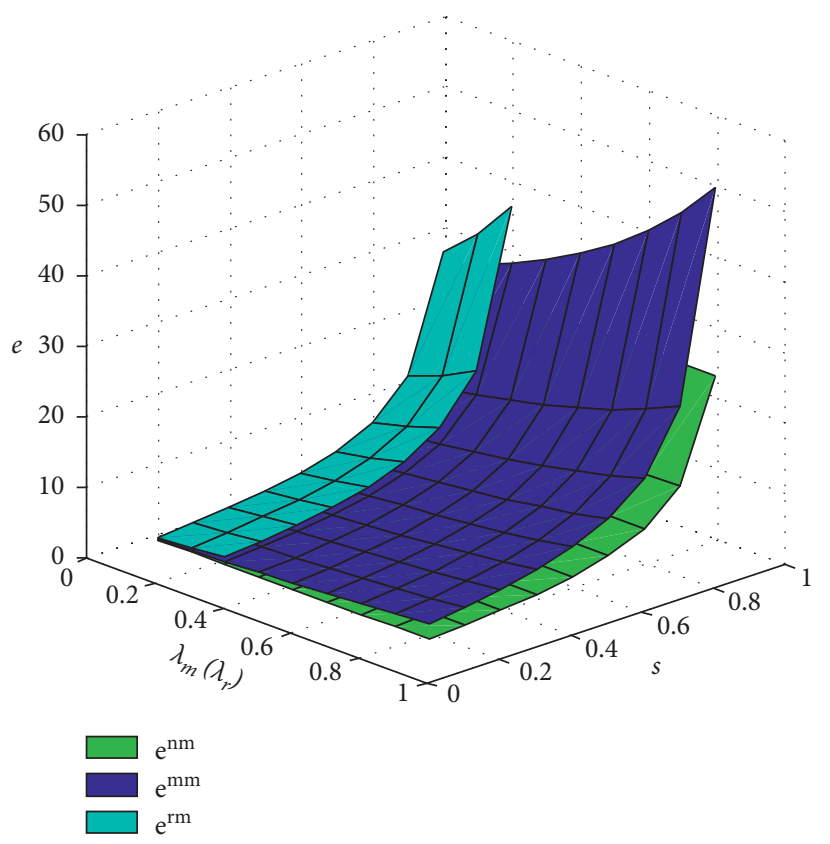

(a)

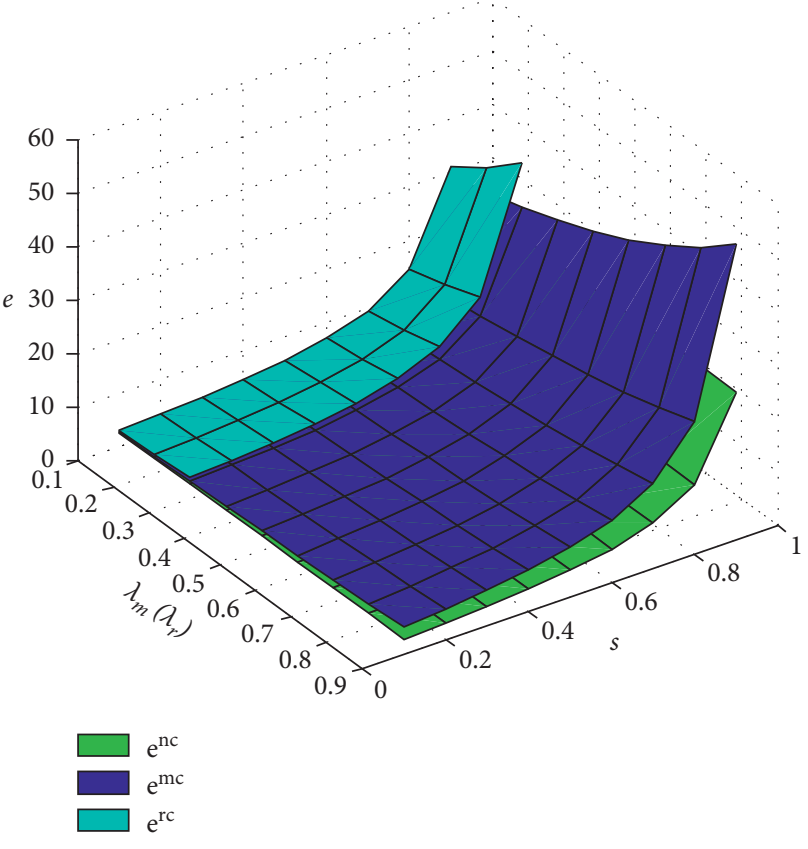

(b)

Figure 1: The impact of $s, \lambda_{m}\left(\lambda_{r}\right)$ on $e$ : (a) Manufacturer subsidy and (b) consumer subsidy.

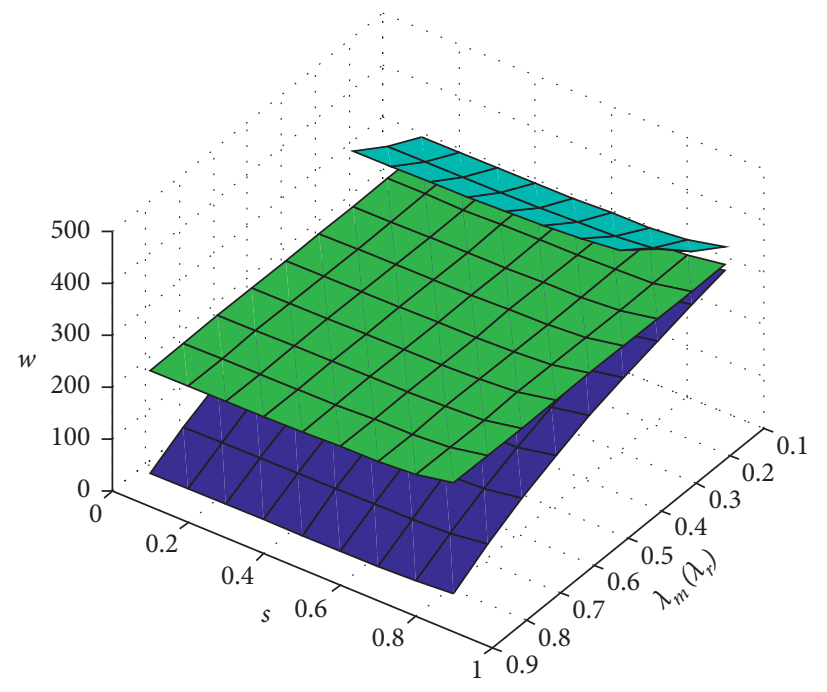

$\square w^{\mathrm{nm}}$
$\square{ }^{\mathrm{mm}}$
$\mathrm{w}^{\mathrm{rm}}$

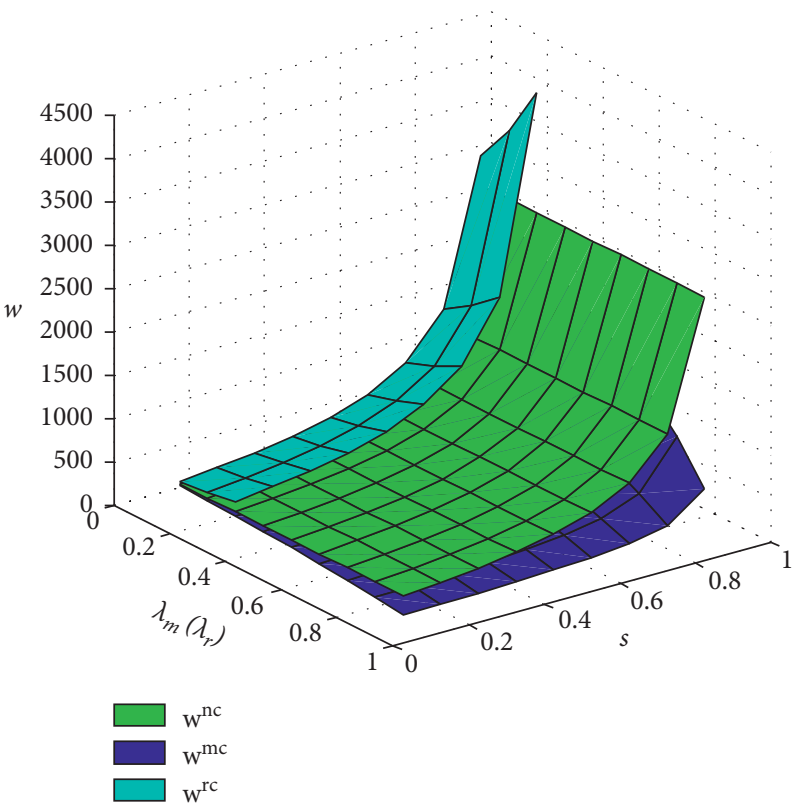

(b)

Figure 2: The impact of $s, \lambda_{m}\left(\lambda_{r}\right)$ on $w$. (a) Manufacturer subsidy and (b) consumer subsidy.

(4) Figure 5 demonstrates that the retailer's profit increases under the manufacturer's altruistic preference as government subsidies increase but decreases as self-altruistic preference increases. When government subsidies are gradually increasing, the retailer's profit will also rise gradually. $\pi_{r}^{r m}<\pi_{r}^{n m}<\pi_{r}^{m m}$ and $\pi_{r}^{r c}<\pi_{r}^{n c}<\pi_{r}^{m c}$ because the joint influence of government subsidies and altruistic preferences on retailer profit is positive.

(5) Figure 6 shows that the overall profit of the supply chain increases with increasing government subsidies and altruistic preferences. This shows that the combination of government subsidies and altruistic preferences promotes the performance 


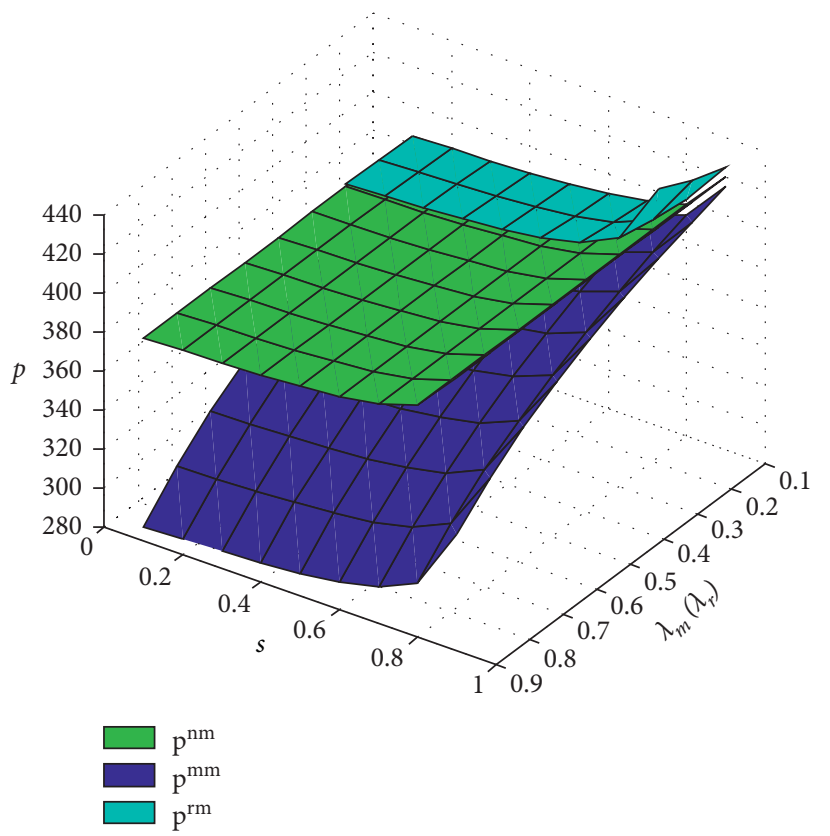

(a)

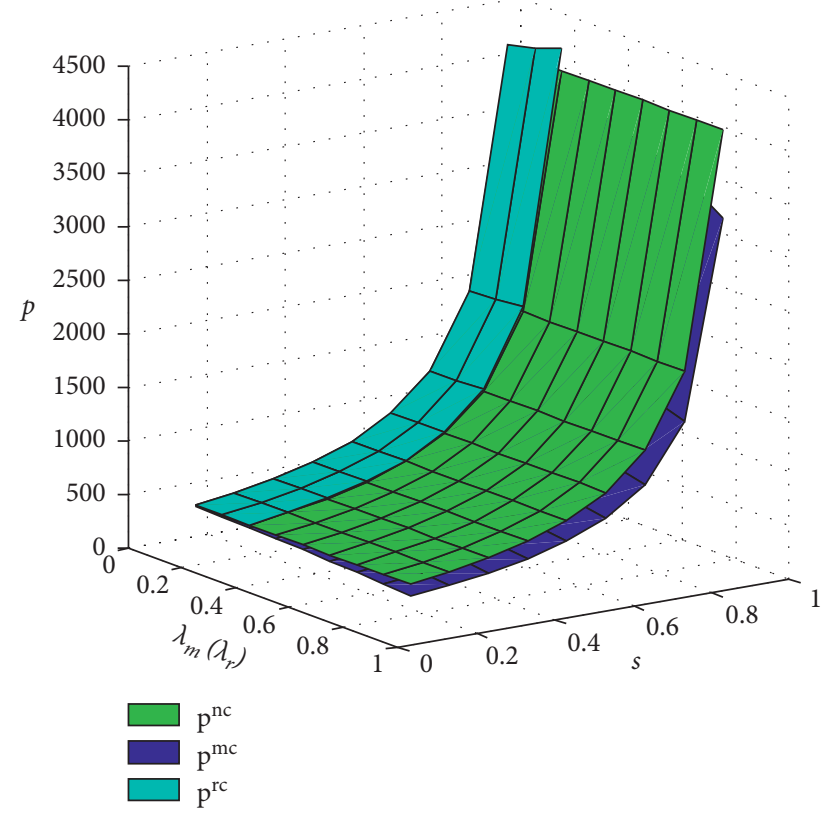

(b)

Figure 3: The impact of $s, \lambda_{m}\left(\lambda_{r}\right)$ on $P$. (a) Manufacturer subsidy and (b) consumer subsidy.

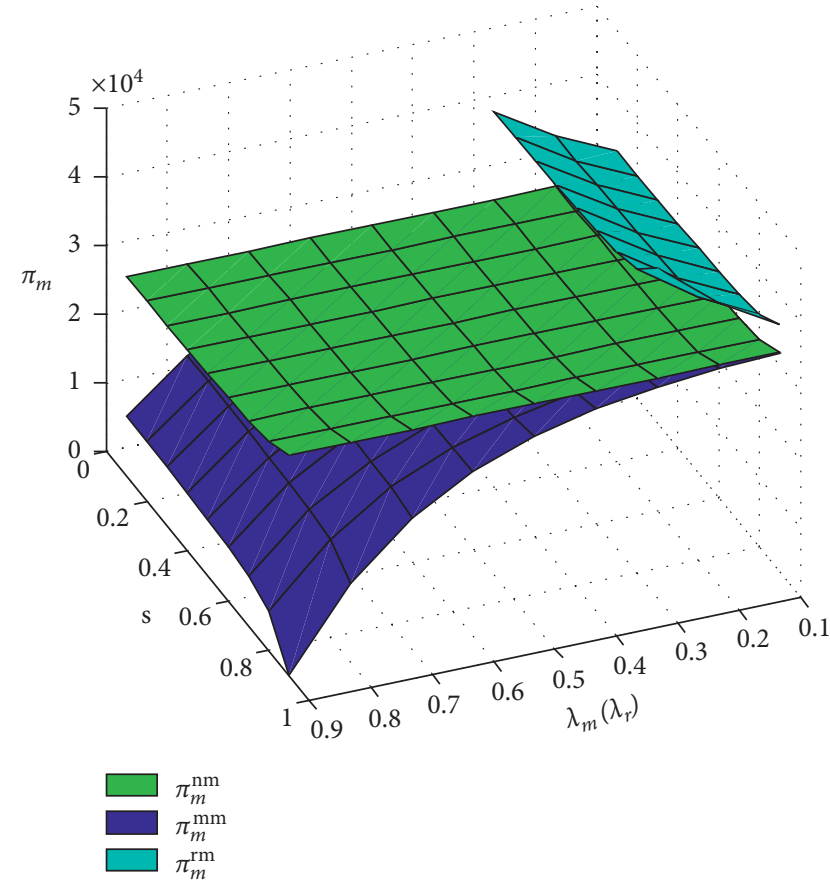

(a)

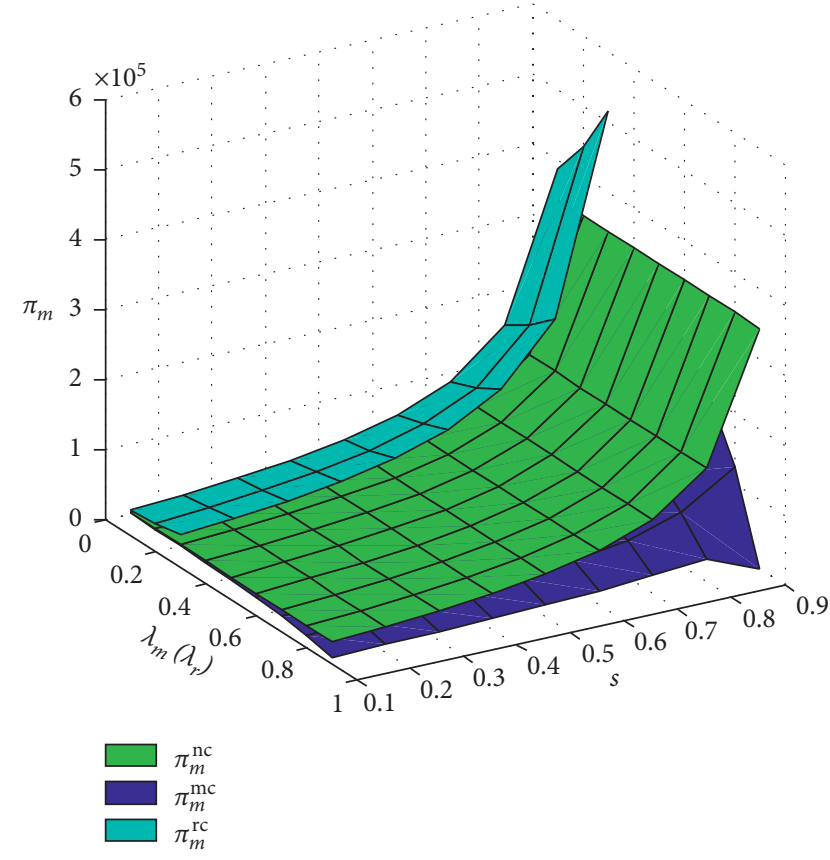

(b)

FIgUre 4: The impact of $s, \lambda_{m}\left(\lambda_{r}\right)$ on $\pi_{m}$. (a) Manufacturer subsidy and (b) consumer subsidy.

of the green supply chain and is conducive to the innovation of green technology, which is better at promoting the development of the green supply chain. Therefore, when formulating government subsidy policies, it is necessary to consider not only the beneficiary of government subsidies but also the influence of the behavioral preferences of supply chain members. This consideration has significance for current policy-makers and managers and is more effective in promoting green innovation and the sustainable development of the green supply chain. 


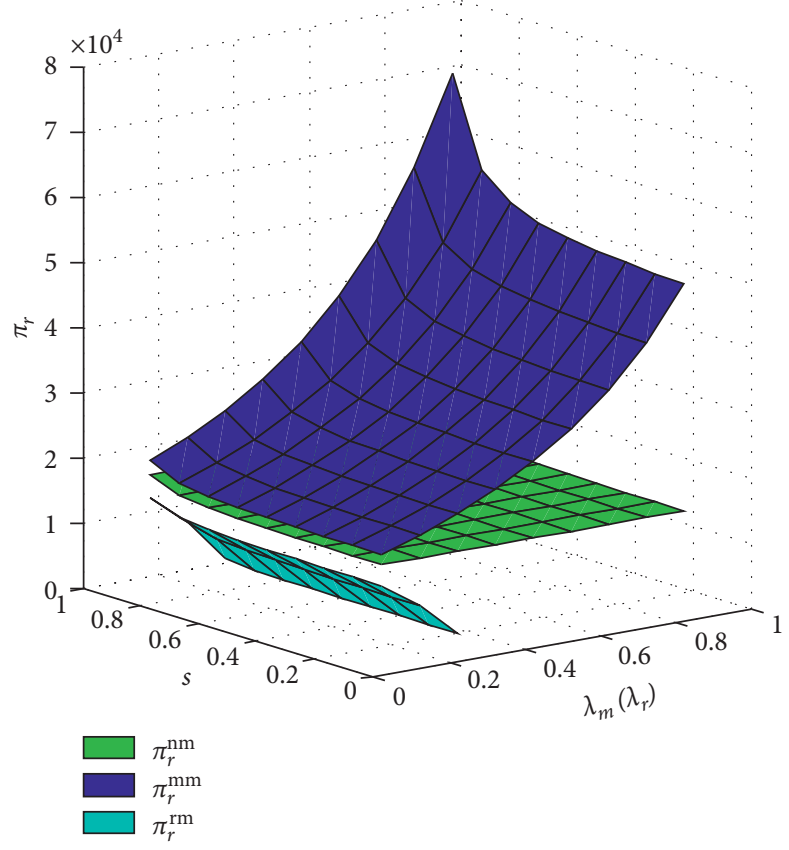

(a)

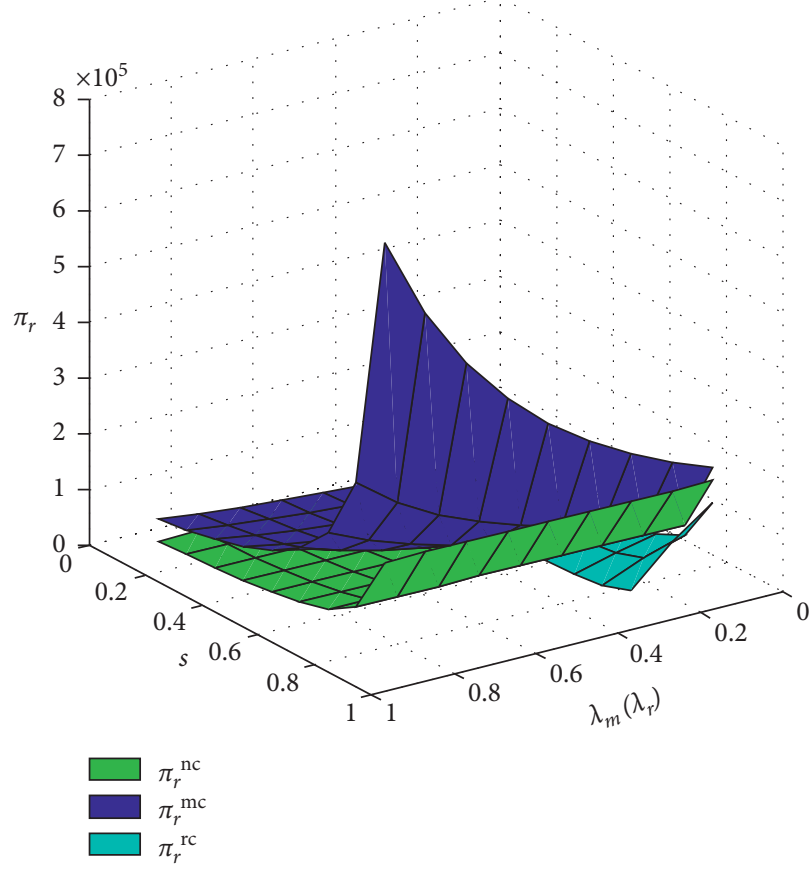

(b)

Figure 5: The impact of $s, \lambda_{m}\left(\lambda_{r}\right)$ on $\pi_{r}$. (a) Manufacturer subsidy and (b) consumer subsidy.

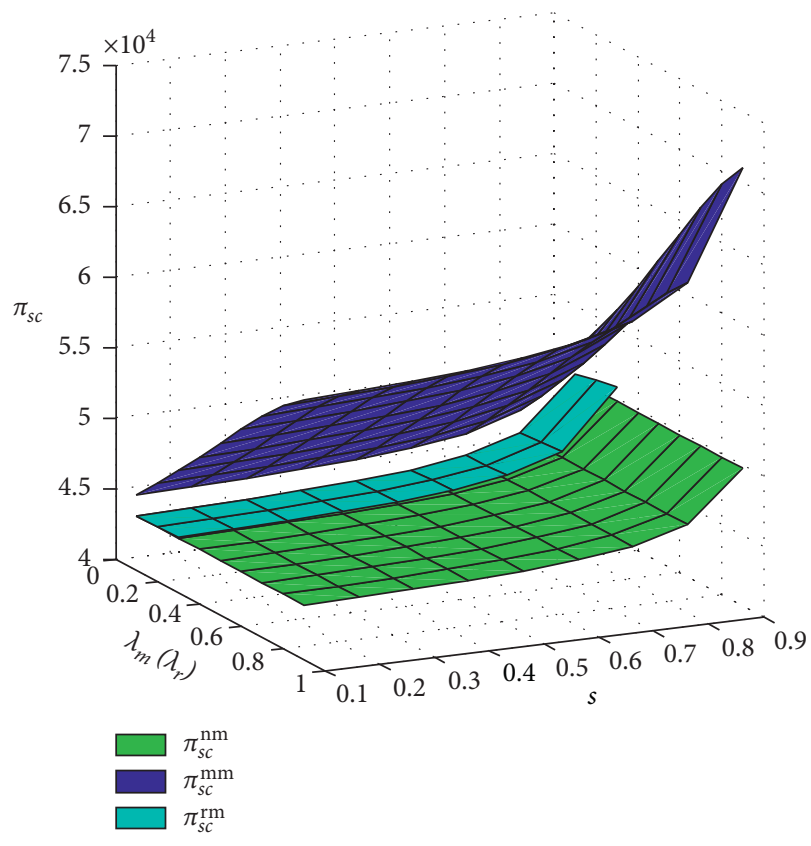

(a)

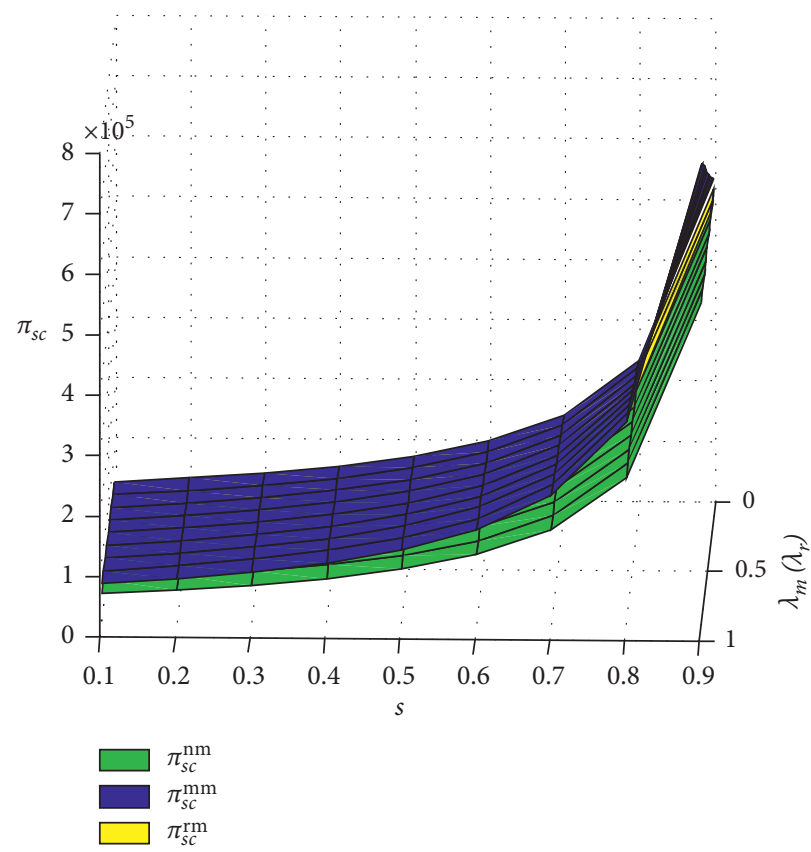

(b)

Figure 6: The impact of $s, \lambda_{m}\left(\lambda_{r}\right)$ on $\pi_{s c}$. (a) Manufacturer subsidy and (b) consumer subsidy.

\section{Conclusions}

Based on the background of green sustainable development, this paper explores the impact of government subsidies and altruistic preferences on green supply chain innovation. The main conclusions of the paper are as follows.
First, under completely self-interested preference, government subsidies to manufacturers or consumers can directly or indirectly encourage manufacturers to improve product greenness, stimulate market demand for green products and promote the development of a green supply chain. However, consumer subsidies are more 
effective in promoting the green supply chain and increasing its members' profits than manufacturer subsidies. Manufacturer subsidies are production-side subsidies, while consumer subsidies are sales-side subsidies. Therefore, when the government promotes the development of the green supply chain, it should provide appropriate green subsidies based on actual conditions to avoid illegal behaviors such as Sai Lin, Jimxi, and other new energy vehicles "Cheating Subsidies."

Second, the altruistic preference of the manufacturer or retailer can increase product greenness, the profit of the other member, and the overall profit of the supply chain, but at a reduction of the manufacturer or retailer's own profit. Manufacturers' willingness to improve product greenness is strengthened under the incentive of government subsidies and altruistic preferences. Compared with the altruistic preference of the manufacturer, the retailer's altruistic preference has a greater effect on improving product greenness, but only within a certain range; otherwise, it will lose profits, which would disrupt the supply chain. Moreover, the profit of the manufacturer decreases as its own altruistic preference increases. When government subsidies exceed a certain range, the decline in profits accelerates. Regardless of whether manufacturers or retailers tend to focus on the interests of partners and have altruistic preferences, this kind of altruistic behavior should be moderate. It is not like NVC's founder Wu Changjiang's "Jianghu loyalty" cooperation that has caused chaos in the entire company and supply chain management, causing greater losses to the entire supply chain, and thus leading to the loss of better development opportunities.

Third, regardless of whether the government subsidies the manufacturer or the consumer, when green innovation efficiency is low, the wholesale and retail prices under the manufacturer's altruistic preference are higher than those under a completely self-interested preference; otherwise, the opposite is true. In the $\mathrm{mm}$ model, higher green innovation efficiency can promote the effect of government subsidies on the profit of the manufacturer. However, the profit of the retailer is also affected by green innovation efficiency and the retailer's altruistic preference. Manufacturers are the leaders of green technology innovation. Although they bear most of the innovation costs, they should increase green innovation efforts to achieve long-term benefits. At the same time, retailers should also make appropriate transfers to encourage manufacturers' willingness to innovate.

In addition, this paper is limited to only considering the manufacturer-dominated game. In future research, a retailer-dominated game will be considered and green supply chain innovation under different power structures will be analyzed. At the same time, this paper only considers altruistic preferences and does not consider other preferences such as fairness concerns and risk aversion preferences. Therefore, in future research, we will further analyze green supply chain innovation when supply chain members have alternate preferences [20, 51-58].

\section{Appendix}

\section{AModel of Subsidizing Manufacturer under Completely Self-Interested Preference $(\mathrm{nm})$}

First, the retailer's profit formula (3) takes the first-order partial derivative of $p$ to obtain $-2 b<0$, and the retailer's profit is a strictly concave function of the retail price of the product. Therefore, there is a unique optimal solution. Seeking $\partial \pi_{r}^{n m^{*}} / \partial p=0$, it can be solved:

$$
p^{n m}=\frac{a+b w+r e}{2 b} .
$$

Then, taking $p^{n m}$ into the manufacturer's profit function (2) and finding the second-order partial derivatives of $w$ and $e$, the Hessian matrix can be obtained:

$$
H=\left(\begin{array}{c}
\frac{\partial^{2} \pi_{m}^{n m}}{\partial w^{2}} \frac{\partial^{2} \pi_{m}^{n m}}{\partial w \partial e} \\
\frac{\partial^{2} \pi_{m}^{n m}}{\partial w \partial e} \frac{\partial^{2} \pi_{m}^{n m}}{\partial e^{2}}
\end{array}\right)=\left(\begin{array}{cc}
-b & \frac{1}{2} r \\
\frac{1}{2} r & k(s-1)
\end{array}\right) .
$$

When $r^{2}-4 b k(1-s)<0$, the Hessian matrix is negative definite, and the manufacturer's profit is the joint concave function of $w$ and $e$, so there is a unique optimal solution. Therefore, by seeking $\partial \pi_{m}^{n m} / \partial w=0$ and $\partial \pi_{m}^{n m} / \partial e=0$ and solving the parallel equations, the manufacturer's optimal wholesale price and product greenness can be obtained as follows:

$$
\begin{aligned}
w^{n m^{*}} & =\frac{2 k(a+b c)(1-s)-c r^{2}}{4 b k(1-s)-r^{2}} \\
e^{n m^{*}} & =\frac{(a-b c) r}{4 b k(1-s)-r^{2}} .
\end{aligned}
$$

Finally, bring $w^{n m^{*}}$ and $e^{n m^{*}}$ into $p^{n m}$ to obtain the retailer's best retail price:

$$
p^{n m^{*}}=\frac{k(3 a+b c)(1-s)-c r^{2}}{4 b k(1-s)-r^{2}} .
$$

Proof completed.

\section{B. Model of Subsidizing Consumers under Completely Self-Interested $(n c)$}

First, the retailer's profit equation (7) is used to obtain the first-order partial derivative of $p$, and the following can be obtained: $-2 b(1-s)<0$. The retailer's profit is a concave function of the retail price of the product, so there is a unique optimal solution. By seeking $\partial \pi_{r}^{n c *} / \partial p=0$, it can be solved:

$$
p^{n c}=\frac{a+r e+b w(1-s)}{2 b(1-s)} .
$$

Then, taking $\begin{gathered}n c \\ p\end{gathered}$ into the manufacturer's profit function (6) and finding the second-order partial derivatives of $w$ and $e$, the Hessian matrix can be obtained: 


$$
H=\left(\begin{array}{cc}
\frac{\partial^{2} \pi_{m}^{n c}}{\partial w^{2}} & \frac{\partial^{2} \pi_{m}^{n c}}{\partial w \partial e} \\
\frac{\partial^{2} \pi_{m}^{n c}}{\partial w \partial e} & \frac{\partial^{2} \pi_{m}^{n c}}{\partial e^{2}}
\end{array}\right)=\left(\begin{array}{cc}
-b(1-s) & \frac{1}{2} r \\
\frac{1}{2} r & -k
\end{array}\right)
$$

When $r^{2}-4 b k(1-s)<0$, the Hessian matrix is negative definite, and the manufacturer's profit is about the joint concave function of $w$ and $e$, so there is a unique optimal solution. Therefore, by solving $\partial \pi_{m}^{n c} / \partial w=0$ and $\partial \pi_{m}^{n c} / \partial e=0$ and solving the set of equations in parallel, the manufacturer's optimal wholesale price and product greenness can be obtained as follows:

$$
\begin{aligned}
w^{n c *} & =\frac{2 a k+2 b c k(1-s)-c r^{2}}{4 b k(1-s)-r^{2}}, \\
e^{n c *} & =\frac{[a-b c(1-s)] r}{4 b k(1-s)-r^{2}}
\end{aligned}
$$

Finally, bring $w^{n c *}$ and $e^{n c *}$ into $p^{n c}$ to obtain the retailer's best retail price:

$$
p^{n c *}=\frac{3 a k+b c k(1-s)-c r^{2}}{4 b k(1-s)-r^{2}} .
$$

Proof completed.

\section{Model of Subsidizing Manufacturer under Altruistic Preference of Manufacturer $(\mathrm{mm})$}

First, the retailer's profit equation (3) is used to obtain the first-order partial derivative of $p$, and then $-2 b<0$, the retailers profit is a strictly concave function of the retail price of the product. Therefore, there is a unique optimal solution. Asking for $\partial \pi_{r}^{m m^{*}} / \partial p=0$, it can be solved:

$$
p^{m m}=\frac{a+b w+r e}{2 b} .
$$

Second, putting $p^{m m}$ into the manufacturer's utility function (11) and finding the second-order partial derivatives of $w$ and $e$, the Hessian matrix can be obtained:

$$
H=\left(\begin{array}{c}
\frac{\partial^{2} U_{m}^{m m}}{\partial w^{2}} \frac{\partial^{2} U_{m}^{m m}}{\partial w \partial e} \\
\frac{\partial^{2} U_{m}^{m m}}{\partial w \partial e} \frac{\partial^{2} U_{m}^{m m}}{\partial e^{2}}
\end{array}\right)=\left(\begin{array}{cc}
\frac{1}{2} b\left(\lambda_{m}-2\right) & -\frac{1}{2} r\left(\lambda_{m}-1\right) \\
-\frac{1}{2} r\left(\lambda_{m}-1\right) & \frac{1}{2 b} \lambda_{m} r^{2}+k(s-1)
\end{array}\right) .
$$

From the above, it can be found that when $r^{2}-2 b k\left(2-\lambda_{m}\right)(1-s)<0$, the Hessian matrix is negative definite, the manufacturer's utility is the joint concave function of the product wholesale price and the product greenness, so there is a unique optimal solution. Therefore, if $\partial \pi_{m}^{m m} / \partial w=0$ and $\partial \pi_{m}^{m m} / \partial e=0$, solving the set of equations in parallel, the optimal wholesale price and product greenness of the manufacturer can be obtained as follows:

$$
\begin{aligned}
w^{m m^{*}} & =\frac{2 k(1-s)\left[a\left(1-\lambda_{m}\right)+b c\right]-c r^{2}}{2 b k\left(2-\lambda_{m}\right)(1-s)-r^{2}}, \\
e^{m m^{*}} & =\frac{(a-b c) r}{2 b k\left(2-\lambda_{m}\right)(1-s)-r^{2}} .
\end{aligned}
$$

Finally, bring $w^{m m^{*}}$ and $e^{m m^{*}}$ into $p^{m m}$ to obtain the retailer's best retail price:

$$
p^{m m^{*}}=\frac{k(1-s)\left[a\left(3-2 \lambda_{m}\right)+b c\right]-c r^{2}}{2 b k\left(2-\lambda_{m}\right)(1-s)-r^{2}} .
$$

Proof completed.

\section{Model of Subsidizing Consumers under Altruistic Preference of Manufacturer $(m c)$}

First, the retailer's profit formula (7) is used to find the firstorder partial derivative of $p$, and then $-2 b(1-s)<0$. The retailer's profit is a concave function of the retail price of a product, so there is a unique optimal solution. By seeking $\partial \pi_{r}^{m c^{*}} / \partial p=0$, it can be solved:

$$
p^{m c}=\frac{a+r e+b w(1-s)}{2 b(1-s)} .
$$

Then, putting $\underset{p}{m c}$ into the manufacturer's utility function (12) and finding the second-order partial derivatives of $w$ and $e$, the Hessian matrix can be obtained:

$$
\begin{aligned}
H & =\left(\begin{array}{c}
\frac{\partial^{2} U_{m}^{m c}}{\partial w^{2}} \frac{\partial^{2} U_{m}^{m c}}{\partial w \partial e} \\
\frac{\partial^{2} U_{m}^{m c}}{\partial w \partial e} \frac{\partial^{2} U_{m}^{m c}}{\partial e^{2}}
\end{array}\right) \\
& =\left(\begin{array}{cc}
-\frac{1}{2} b\left(2-\lambda_{m}\right)(1-s) & \frac{1}{2}\left(1-\lambda_{m}\right) r \\
\frac{1}{2}\left(1-\lambda_{m}\right) r & \frac{\lambda_{m} r^{2}}{2 b(1-s)}-k
\end{array}\right) .
\end{aligned}
$$

From the above, it can be found that when $r^{2}-2 b k(1-s)\left(2-\lambda_{m}\right)<0$, the Hessian matrix is negative definite, and the manufacturer's utility is the joint concave function of $w$ and $e$, so there is a unique optimal solution. Therefore, letting $\partial \pi_{m}^{m c} / \partial w=0$ and $\partial \pi_{m}^{m c} / \partial e=0$ and solving the set of equations in parallel, the optimal wholesale price and product greenness of the manufacturer can be obtained as follows:

$$
\begin{aligned}
w^{m c^{*}} & =\frac{2 a k\left(1-\lambda_{m}\right)+2 b c k(1-s)-c r^{2}}{2 b k(1-s)\left(2-\lambda_{m}\right)-r^{2}}, \\
e^{m c^{*}} & =\frac{[a-b c(1-s)] r}{2 b k(1-s)\left(2-\lambda_{m}\right)-r^{2}} .
\end{aligned}
$$

Finally, bring $w^{m c^{*}}$ and $e^{m c^{*}}$ into $p^{m c}$ to obtain the retailer's best retail price: 


$$
p^{m c^{*}}=\frac{a k\left(3-2 \lambda_{m}\right)+b c k(1-s)-c r^{2}}{2 b k(1-s)\left(2-\lambda_{m}\right)-r^{2}} .
$$

Proof completed.

\section{E. Model of the Subsidizing Manufacturer under the Altruistic Preference of the Retailer $(\mathrm{rm})$}

First, the retailer's utility function (13) is used to find the first-order partial derivative of $p$, and then $-2 b<0$. The retailer's utility is a concave function of the retail price of the product, so there is a unique optimal solution. By seeking $\partial U_{r}^{r m^{*}} / \partial p=0$, it can be solved:

$$
p^{r m}=\frac{a+b w+r e-b \lambda_{r}(w-c)}{2 b} .
$$

Then, taking $p^{r m}$ into the manufacturer's profit function (2) and finding the second-order partial derivatives of $w$ and $e$, the Hessian matrix can be obtained as follows:

$$
H=\left(\begin{array}{cc}
\frac{\partial^{2} \pi_{m}^{r m}}{\partial w^{2}} & \frac{\partial^{2} \pi_{m}^{r m}}{\partial w} \partial \\
\frac{\partial^{2} \pi_{m}^{r m}}{\partial w \partial e} & \frac{\partial^{2} \pi_{m}^{r m}}{\partial e^{2}}
\end{array}\right)=\left(\begin{array}{cc}
b\left(\lambda_{r}-1\right) & \frac{1}{2} r \\
\frac{1}{2} r & k(s-1)
\end{array}\right) .
$$

From the above, it can be found that when $r^{2}-4 b k\left(1-\lambda_{r}\right)(1-s)<0$, the Hessian matrix is negative definite, and the manufacturer's profit is the joint concave function of $w$ and $e$. Let $\partial \pi_{m}^{r m} / \partial w=0$ and $\partial \pi_{m}^{r m} / \partial e=0$; solving the parallel equations, the manufacturer's optimal wholesale price and product greenness can be obtained as follows:

$$
\begin{aligned}
w^{r m^{*}} & =\frac{2 k(1-s)\left[a+b c\left(1-2 \lambda_{r}\right)\right]-c r^{2}}{4 b k\left(1-\lambda_{r}\right)(1-s)-r^{2}}, \\
e^{r m^{*}} & =\frac{(a-b c) r}{4 b k\left(1-\lambda_{r}\right)(1-s)-r^{2}} .
\end{aligned}
$$

Finally, taking $w^{r m^{*}}$ and $e^{r m^{*}}$ into $p^{r m}$ to obtain the retailer's best retail price,

$$
p^{r m^{*}}=\frac{\left(1-\lambda_{r}\right)(1-s)(3 a+b c) k-c r^{2}}{4 b k\left(1-\lambda_{r}\right)(1-s)-r^{2}} .
$$

Proof completed.

\section{F. Model of Subsidizing Consumers under the Altruistic Preference of Retailers $(r c)$}

First, the retailer's utility function (14) is used to find the first-order partial derivative of $p$, and then $-2 b(1-s)<0$. The retailer's utility is a concave function of the retail price of the product, so there is a unique optimal solution. By seeking $\partial U_{r}^{r c *} / \partial p=0$, it can be solved:

$$
p^{r c}=\frac{a+r e+b w(1-s)-b \lambda_{r}(w-c)(1-s)}{2 b(1-s)} .
$$

Then, taking $p^{r c}$ into the manufacturer's profit function (6) and finding the second-order partial derivatives of $w$ and $e$, the Hessian matrix can be obtained:

$H=\left(\begin{array}{cc}\frac{\partial^{2} \pi_{m}^{r c}}{\partial w^{2}} & \frac{\partial^{2} \pi_{m}^{r c}}{\partial w \partial e} \\ \frac{\partial^{2} \pi_{m}^{r c}}{\partial w \partial e} & \frac{\partial^{2} \pi_{m}^{r c}}{\partial e^{2}}\end{array}\right)=\left(\begin{array}{cc}-b\left(1-\lambda_{r}\right)(1-s) & \frac{1}{2} r \\ \frac{1}{2} r & -k\end{array}\right)$.

It can be obtained from the above, when $r^{2}-4 b k\left(1-\lambda_{r}\right)(1-s)<0$, the Hessian matrix is negative definite, and the manufacturer's profit is the joint concave function of $w$ and $e$, so there is a unique optimal solution. Let $\partial \pi_{m}^{r c} / \partial w=0$ and $\partial \pi_{m}^{r c} / \partial e=0$; solving the parallel equations, the manufacturer's optimal wholesale price and product greenness can be obtained as follows:

$$
\begin{aligned}
w^{r c *} & =\frac{2 k\left[a+b c(1-s)\left(1-2 \lambda_{r}\right)\right]-c r^{2}}{4 b k(1-s)\left(1-\lambda_{r}\right)-r^{2}}, \\
e^{r c *} & =\frac{[a-b c(1-s)] r}{4 b k(1-s)\left(1-\lambda_{r}\right)-r^{2}} .
\end{aligned}
$$

Finally, taking $w^{r c *}$ and $e^{r c *}$ into $p^{r c}$ to find the retailer's optimal retail price:

$p^{r c *}=\frac{3 a k\left(1-\lambda_{r}\right)+b c k\left(1-\lambda_{r}\right)(1-s)-c r^{2}}{4 b k(1-s)\left(1-\lambda_{r}\right)-r^{2}}$.

Proof completed.

\section{G. Corollary 1:}

(1) Finding the first-order partial derivatives of $e^{i *}$, with respect to $s, \lambda_{m}$, and $\lambda_{r}$ respectively, we can get the following:

$$
\begin{aligned}
\frac{\partial e^{n m^{*}}}{\partial s} & =\frac{4 b k r(a-b c)}{\left[4 b k(1-s)-r^{2}\right]^{2}}>0, \\
\frac{\partial e^{m m^{*}}}{\partial s} & =\frac{2 b k r(a-b c)\left(2-\lambda_{m}\right)}{\left[2 b k\left(2-\lambda_{m}\right)(1-s)-r^{2}\right]^{2}}, \\
\frac{\partial e^{r m^{*}}}{\partial \lambda_{r}} & =\frac{4 b k r(a-b c)(1-s)}{\left[4 b k\left(1-\lambda_{r}\right)(1-s)-r^{2}\right]^{2}}>0, \\
\frac{\partial e^{n c *}}{\partial s} & =\frac{b r\left(4 a k-c r^{2}\right)}{\left[4 b k(1-s)-r^{2}\right]^{2}}>0, \\
\frac{\partial e^{m c^{*}}}{\partial s} & =\frac{b r\left[2 a k\left(2-\lambda_{m}\right)-c r^{2}\right]}{\left[2 b k\left(2-\lambda_{m}\right)(1-s)-r^{2}\right]^{2}}>0, \\
\frac{\partial e^{r c *}}{\partial \lambda_{r}} & =\frac{4 b k r(a-b c+b c s)(1-s)}{\left[4 b k\left(1-\lambda_{r}\right)(1-s)-r^{2}\right]^{2}}>0,
\end{aligned}
$$




$$
\begin{aligned}
\frac{\partial e^{m m^{*}}}{\partial \lambda_{m}} & =\frac{2 b k r(1-s)(a-b c)}{\left[2 b k\left(2-\lambda_{m}\right)(1-s)-r^{2}\right]^{2}}>0, \\
\frac{\partial e^{m c^{*}}}{\partial \lambda_{m}} & =\frac{2 b k r(1-s)(a-b c+b c s)}{\left[2 b k\left(2-\lambda_{m}\right)(1-s)-r^{2}\right]^{2}}>0, \\
\frac{\partial e^{r m^{*}}}{\partial \lambda_{r}} & =\frac{4 b k r(1-s)(a-b c)}{\left[4 b k\left(1-\lambda_{r}\right)(1-s)-r^{2}\right]^{2}}>0, \\
\frac{\partial e^{r c *}}{\partial \lambda_{r}} & =\frac{4 b k r(1-s)(a-b c+b c s)}{\left[4 b k\left(1-\lambda_{r}\right)(1-s)-r^{2}\right]^{2}}>0, \\
\frac{\partial^{2} e}{\partial \lambda_{m} \partial s} & =\frac{4 b^{2} k^{2} r^{2}(a-b c)^{2}\left[2 b k(1-s)\left(2-\lambda_{m}\right)+r^{2}\right]}{\left[2 b k(1-s)\left(2-\lambda_{m}\right)-r^{2}\right]}>0, \\
\frac{\partial^{2} e}{\partial \lambda_{r} \partial s} & =\frac{16 b^{2} k^{2} r^{2}(a-b c)^{2}\left[12 b k(1-s)\left(1-\lambda_{r}\right)+r^{2}\right]}{\left[4 b k(1-s)\left(1-\lambda_{r}\right)-r^{2}\right]}>0 .
\end{aligned}
$$

(2) Using the difference method to compare the greenness:

$$
\begin{aligned}
e^{r m^{*}}-e^{m m^{*}} & =\frac{2 b k r(1-s)(a-b c)\left(2 \lambda_{r}-\lambda_{m}\right)}{\left[2 b k(1-s)\left(2-\lambda_{m}\right)-r^{2}\right]\left[4 b k(1-s)\left(1-\lambda_{r}\right)-r^{2}\right]}>0, \\
e^{r m^{*}}-e^{n m^{*}} & =\frac{4 b k r \lambda_{r}(1-s)(a-b c)}{\left[4 b k(1-s)-r^{2}\right]\left[4 b k(1-s)\left(1-\lambda_{r}\right)-r^{2}\right]}>0, \\
e^{m m^{*}}-e^{n m^{*}} & =\frac{2 b k r \lambda_{m}(1-s)(a-b c)}{\left[4 b k(1-s)-r^{2}\right]\left[2 b k(1-s)\left(2-\lambda_{m}\right)-r^{2}\right]}>0 .
\end{aligned}
$$

Therefore, $e^{r m^{*}}>e^{m m^{*}}>e^{n m^{*}}$.

$$
\begin{aligned}
e^{r c *}-e^{m c^{*}} & =\frac{2 b k r(1-s)[a-b c(1-s)]\left(2 \lambda_{r}-\lambda_{m}\right)}{\left[2 b k(1-s)\left(2-\lambda_{m}\right)-r^{2}\right]\left[4 b k(1-s)\left(1-\lambda_{r}\right)-r^{2}\right]}>0, \\
e^{r c *}-e^{n c *} & =\frac{4 b k r \lambda_{r}(1-s)[a-b c(1-s)]}{\left[4 b k(1-s)-r^{2}\right]\left[4 b k(1-s)\left(1-\lambda_{r}\right)-r^{2}\right]}>0, \\
e^{m c^{*}}-e^{n c *} & =\frac{2 b k r \lambda_{m}(1-s)[a-b c(1-s)]}{\left[4 b k(1-s)-r^{2}\right]\left[2 b k(1-s)\left(2-\lambda_{m}\right)-r^{2}\right]}>0 .
\end{aligned}
$$

Therefore, $e^{r c *}>e^{m c^{*}}>e^{n c *}$. 


\section{H. Corollary 2}

(1) Find the first-order partial derivatives of $w^{i *}$ and $p^{i *}$, with respect to $s, \lambda_{m}$, and $\lambda_{r}$, respectively; we can get the following:

$$
\begin{aligned}
& \frac{\partial w^{n m^{*}}}{\partial s}=\frac{2 k r^{2}(a-b c)}{\left[4 b k(1-s)-r^{2}\right]^{2}}>0, \\
& \frac{\partial p^{n m^{*}}}{\partial s}=\frac{3 k r^{2}(a-b c)}{\left[4 b k(1-s)-r^{2}\right]^{2}}>0, \\
& \frac{\partial w^{n c *}}{\partial s}=\frac{2 b k\left(4 a k-c r^{2}\right)}{4 b k(1-s)-r^{2}}>0, \\
& \frac{\partial p^{n c *}}{\partial s}=\frac{3 b k\left(4 a k-c r^{2}\right)}{4 b k(1-s)-r^{2}}>0, \\
& \frac{\partial w^{m m^{*}}}{\partial s}=\frac{2 k r^{2}(a-b c)\left(1-\lambda_{m}\right)}{\left[2 b k\left(2-\lambda_{m}\right)(1-s)-r^{2}\right]^{2}}>0, \\
& \frac{\partial p^{m m^{*}}}{\partial s}=\frac{k r^{2}(a-b c)\left(3-2 \lambda_{m}\right)}{\left[2 b k\left(2-\lambda_{m}\right)(1-s)-r^{2}\right]^{2}}>0, \\
& \frac{\partial w^{m c^{*}}}{\partial s}=\frac{2 b k\left(1-\lambda_{m}\right)\left[2 a k\left(2-\lambda_{m}\right)-c r^{2}\right]}{\left[2 b k(1-s)\left(2-\lambda_{m}\right)-r^{2}\right]^{2}}>0, \\
& \frac{\partial p^{m c^{*}}}{\partial s}=\frac{b k\left(3-2 \lambda_{m}\right)\left[2 a k\left(2-\lambda_{m}\right)-c r^{2}\right]}{\left[2 b k(1-s)\left(2-\lambda_{m}\right)-r^{2}\right]^{2}}>0, \\
& \frac{\partial w^{r m^{*}}}{\partial s}=\frac{2 k r^{2}(a-b c)}{\left[4 b k\left(1-\lambda_{r}\right)(1-s)-r^{2}\right]^{2}}>0, \\
& \frac{\partial p^{r m^{*}}}{\partial s}=\frac{3 k r^{2}\left(1-\lambda_{r}\right)(a-b c)}{\left[4 b k\left(1-\lambda_{r}\right)(1-s)-r^{2}\right]^{2}}>0,
\end{aligned}
$$

$$
\begin{aligned}
& \frac{\partial w^{r c *}}{\partial s}=\frac{2 b k\left[4 a k\left(1-\lambda_{r}\right)-c r^{2}\right]}{\left[4 b k(1-s)\left(1-\lambda_{r}\right)-r^{2}\right]^{2}}>0, \\
& \frac{\partial p^{r c *}}{\partial s}=\frac{3 b k\left(1-\lambda_{r}\right)\left[4 a k\left(1-\lambda_{r}\right)-c r^{2}\right]}{\left[4 b k(1-s)\left(1-\lambda_{r}\right)-r^{2}\right]^{2}}>0, \\
& \frac{\partial w^{r m^{*}}}{\partial \lambda_{r}}=\frac{8 b k^{2}(1-s)^{2}(a-b c)}{\left[4 b k\left(1-\lambda_{r}\right)(1-s)-r^{2}\right]^{2}}>0, \\
& \frac{\partial p^{r m^{*}}}{\partial \lambda_{r}}=\frac{3 k r^{2}(1-s)(a-b c)}{\left[4 b k\left(1-\lambda_{r}\right)(1-s)-r^{2}\right]^{2}}>0, \\
& \frac{\partial w^{r c *}}{\partial \lambda_{r}}=\frac{8 b k^{2}(1-s)[a-b c(1-s)]}{\left[4 b k(1-s)\left(1-\lambda_{r}\right)-r^{2}\right]^{2}}>0, \\
& \frac{\partial p^{r c *}}{\partial \lambda_{r}}=\frac{3 k r^{2}[a-b c(1-s)]}{\left[4 b k(1-s)\left(1-\lambda_{r}\right)-r^{2}\right]^{2}}>0, \\
& \frac{\partial w^{m m^{*}}}{\partial \lambda_{m}}=\frac{2 k(1-s)(a-b c)\left[r^{2}-2 b k(1-s)\right]}{\left[2 b k\left(2-\lambda_{m}\right)(1-s)-r^{2}\right]^{2}}, \\
& \frac{\partial p^{m m^{*}}}{\partial \lambda_{m}}=\frac{2 k(1-s)(a-b c)\left[r^{2}-b k(1-s)\right]}{\left[2 b k\left(2-\lambda_{m}\right)(1-s)-r^{2}\right]^{2}}, \\
& \frac{\partial w^{m c^{*}}}{\partial \lambda_{m}}=\frac{2 k[a-b c(1-s)]\left[r^{2}-2 b k(1-s)\right]}{\left[2 b k(1-s)\left(2-\lambda_{m}\right)-r^{2}\right]^{2}}, \\
& {\left[2 b k(1-s)\left(2-\lambda_{m}\right)-r^{2}\right]^{2}}
\end{aligned},
$$

From the above, when $A<k / r^{2}<1 / 2 b(1-s)$, $\partial w^{x *} / \partial \lambda_{m}>0$ and $\partial p^{x *} / \partial \lambda_{m}>0$ and when $k / r^{2}>1 / b(1-s), \partial w^{x *} / \partial \lambda_{m}<0$ and $\partial p^{x *} / \partial \lambda_{m}<0$ $(x=m m, m c)$.

(2) Using the difference method to compare the wholesale price and retail price of the product:

$$
\begin{aligned}
w^{r m^{*}}-w^{m m^{*}} & =\frac{2 k(1-s)(a-b c)\left[2 b k(1-s)\left[\lambda_{m}+2 \lambda_{r}\left(1-\lambda_{m}\right)\right]-\lambda_{m} r^{2}\right]}{\left[2 b k(1-s)\left(2-\lambda_{m}\right)-r^{2}\right]\left[4 b k(1-s)\left(1-\lambda_{r}\right)-r^{2}\right]}>0, \\
w^{r m^{*}}-w^{n m^{*}} & =\frac{8 b k^{2} \lambda_{r}(1-s)^{2}(a-b c)}{\left[4 b k(1-s)-r^{2}\right]\left[4 b k(1-s)\left(1-\lambda_{r}\right)-r^{2}\right]}>0, \\
w^{m m^{*}}-w^{n m^{*}} & =\frac{2 k \lambda_{m}\left[r^{2}-2 b k(1-s)\right](1-s)(a-b c)}{\left[4 b k(1-s)-r^{2}\right]\left[2 b k(1-s)\left(2-\lambda_{m}\right)-r^{2}\right]},
\end{aligned}
$$




$$
\begin{aligned}
w^{r c *}-w^{m c^{*}} & =\frac{2 k[a-b c(1-s)]\left[2 b k(1-s)\left[\lambda_{m}+2 \lambda_{r}\left(1-\lambda_{m}\right)\right]-\lambda_{m} r^{2}\right]}{\left[2 b k(1-s)\left(2-\lambda_{m}\right)-r^{2}\right]\left[4 b k(1-s)\left(1-\lambda_{r}\right)-r^{2}\right]}>0, \\
w^{r c *}-w^{n c *} & =\frac{8 b k^{2} \lambda_{r}(1-s)[a-b c(1-s)]}{\left[4 b k(1-s)-r^{2}\right]\left[4 b k(1-s)\left(1-\lambda_{r}\right)-r^{2}\right]}>0, \\
w^{m c^{*}}-w^{n c *} & =\frac{2 k \lambda_{m}\left[r^{2}-2 b k(1-s)\right][a-b c(1-s)]}{\left[4 b k(1-s)-r^{2}\right]\left[2 b k(1-s)\left(2-\lambda_{m}\right)-r^{2}\right]}, \\
p^{r m^{*}}-p^{m m^{*}} & =\frac{k(1-s)(a-b) c\left[2 b k \lambda_{m}\left(1-\lambda_{r}\right)(1-s)+\left(3 \lambda_{r}-2 \lambda_{m}\right) r^{2}\right]}{\left[2 b k(1-s)\left(2-\lambda_{m}\right)-r^{2}\right]\left[4 b k(1-s)\left(1-\lambda_{r}\right)-r^{2}\right]}>0, \\
p^{r m^{*}}-p^{n m^{*}} & =\frac{3 \lambda_{r} k r^{2}(1-s)(a-b c)}{\left[4 b k(1-s)-r^{2}\right]\left[4 b k(1-s)\left(1-\lambda_{r}\right)-r^{2}\right]}>0, \\
p^{m m^{*}}-p^{n m^{*}} & =\frac{2 k \lambda_{m}\left[r^{2}-b k(1-s)\right](1-s)(a-b c)}{\left[4 b k(1-s)-r^{2}\right]\left[2 b k(1-s)\left(2-\lambda_{m}\right)-r^{2}\right]}, \\
p^{r c *}-p^{m c^{*}} & =\frac{k[a-b c(1-s)]\left[2 b k \lambda_{m}\left(1-\lambda_{r}\right)(1-s)+\left(3 \lambda_{r}-2 \lambda_{m}\right) r^{2}\right]}{\left[2 b k(1-s)\left(2-\lambda_{m}\right)-r^{2}\right]\left[4 b k(1-s)\left(1-\lambda_{r}\right)-r^{2}\right]}>0, \\
p^{r c *}-p^{n c *} & =\frac{3 \lambda_{r} k r^{2}[a-b c(1-s)]}{\left[4 b k(1-s)-r^{2}\right]\left[4 b k(1-s)\left(1-\lambda_{r}\right)-r^{2}\right]}>0, \\
p^{*}-p^{n c *} & =\frac{2 k \lambda_{m}\left[r^{2}-b k(1-s)\right][a-b c(1-s)]}{\left[4 b k(1-s)-r^{2}\right]\left[2 b k(1-s)\left(2-\lambda_{m}\right)-r^{2}\right]}>0 .
\end{aligned}
$$

From the above, when $A<k / r^{2}<1 / 2 b(1-s)$, $w^{r m^{*}}>w^{m m^{*}}>w^{n m^{*}}, \quad p^{r m^{*}}>p^{m m^{*}}>p^{n m^{*}}$ and when $w^{r c *}>w^{m c^{*}}>w^{n c *}$, and $p^{r c *}>p^{m c^{*}}>p^{n c *}$; when $k / r^{2}$ $>1 / b(1-s)$; when $w^{r m^{*}}>w^{n m^{*}}>w^{m m^{*}}, \quad p^{r m^{*}}>p^{n m^{*}}$ $>p^{m m^{*}}$; when $w^{r c *}>w^{n c *}>w^{m c^{*}}, p^{r c *}>p^{n c *}>p^{m c^{*}}$.

\section{Corollary 3: Prove the following}

(1) Find the first-order partial derivatives of the manufacturer's profit with respect to $s, \lambda_{m}$, and $\lambda_{r}$ to obtain

$$
\begin{aligned}
\frac{\partial \pi_{m}^{n m^{*}}}{\partial s} & =\frac{k r^{2}(a-b c)^{2}}{2\left[4 b k(1-s)-r^{2}\right]^{2}}>0, \\
\frac{\partial \pi_{m}^{r m^{*}}}{\partial s} & =\frac{k r^{2}(a-b c)^{2}}{2\left[4 b k\left(1-\lambda_{r}\right)(1-s)-r^{2}\right]^{2}}>0, \\
\frac{\partial \pi_{m}^{m m^{*}}}{\partial \lambda_{m}} & =\frac{4 b^{2} k^{3}(a-b c)^{2}(s-1)^{3}}{\left[2 b k\left(2-\lambda_{m}\right)(1-s)-r^{2}\right]^{3}}<0,
\end{aligned}
$$

$$
\begin{aligned}
\frac{\partial \pi_{m}^{m c^{*}}}{\partial_{\lambda}^{m}} & =\frac{4 b^{2} k^{3} \lambda_{m}(1-s)^{2}[a-b c(1-s)]^{2}}{\left[r^{2}-2 b k(1-s)\left(2-\lambda_{m}\right)\right]^{3}}<0, \\
\frac{\partial \pi_{m}^{r m^{*}}}{\partial \lambda_{r}} & =\frac{2 b k^{2}(1-s)^{2}(a-b c)^{2}}{\left[4 b k\left(1-\lambda_{r}\right)(1-s)-r^{2}\right]^{2}}>0, \\
\frac{\partial \pi_{m}^{r * *}}{\partial \lambda_{r}} & =\frac{2 b k^{2}(1-s)[a-b c(1-s)]^{2}}{\left[4 b k(1-s)\left(1-\lambda_{r}\right)-r^{2}\right]^{2}}>0, \\
\frac{\partial \pi_{m}^{m m^{*}}}{\partial s} & =\frac{k r^{2}(a-b c)^{2}\left[2 b k\left(2-3 \lambda_{m}\right)(1-s)-r^{2}\right]}{2\left[2 b k\left(2-\lambda_{m}\right)(1-s)-r^{2}\right]^{3}} .
\end{aligned}
$$

When $0<\lambda_{m}<2 / 3$ and $k / r^{2}>1 / 2 b\left(2-3 \lambda_{m}\right)(1-s)$, $\partial \pi_{m}^{m m^{*}} / \partial s>0$. When $0<\lambda_{m}<2 / 3, A<k / r^{2}<1 / 2 b(2$ $\left.-3 \lambda_{m}\right)(1-s)$ or when $2 / 3<\lambda_{m}<1, \partial \pi_{m}^{m m^{*}} / \partial s<0$.

(2) Using the difference method to compare the manufacturer's profit separately: 


$$
\begin{aligned}
& \pi_{m}^{r m^{*}}-\pi_{m}^{m m^{*}}=\frac{2 b k^{2}(1-s)^{2}(a-b c)^{2}\left[4 b k \lambda_{r}(1-s)\left(1+\lambda_{m}\right)+b k \lambda_{m}^{2}(1-s)-\lambda_{r} r^{2}\right]}{\left[2 b k(1-s)\left(2-\lambda_{m}\right)-r^{2}\right]^{2}\left[4 b k(1-s)\left(1-\lambda_{r}\right)-r^{2}\right]}>0, \\
& \pi_{m}^{r m^{*}}-\pi_{m}^{n m^{*}}=\frac{2 b k^{2} \lambda_{r}(1-s)^{2}(a-b c)^{2}}{\left[4 b k(1-s)-r^{2}\right]\left[4 b k(1-s)\left(1-\lambda_{r}\right)-r^{2}\right]}>0, \\
& \pi_{m}^{m m^{*}}-\pi_{m}^{n m^{*}}=\frac{2 b^{2} k^{3} \lambda_{m}^{2}(s-1)^{3}(a-b c)^{2}}{\left[4 b k(1-s)-r^{2}\right]\left[2 b k(1-s)\left(2-\lambda_{m}\right)-r^{2}\right]^{2}}<0, \\
& \pi_{m}^{r c *}-\pi_{m}^{m c^{*}}=\frac{2 b k^{2}(1-s)[a-b c(1-s)]^{2}\left[4 b k \lambda_{r}(1-s)\left(1-\lambda_{m}\right)+b k \lambda_{m}^{2}(1-s)-\lambda_{r} r^{2}\right]}{\left[2 b k(1-s)\left(2-\lambda_{m}\right)-r^{2}\right]^{2}\left[4 b k(1-s)\left(1-\lambda_{r}\right)-r^{2}\right]}>0, \\
& \pi_{m}^{r c *}-\pi_{m}^{n c *}=\frac{2 b k^{2} \lambda_{r}(1-s)[a-b c(1-s)]^{2}}{\left[4 b k(1-s)-r^{2}\right]\left[4 b k(1-s)\left(1-\lambda_{r}\right)-r^{2}\right]}>0, \\
& \pi_{m}^{m c^{*}}-\pi_{m}^{n c *}=\frac{2 b^{2} k^{3} \lambda_{m}^{2}(1-s)^{2}[a-b c(1-s)]^{2}}{\left[r^{2}-4 b k(1-s)\right]\left[2 b k(1-s)\left(2-\lambda_{m}\right)-r^{2}\right]}<0 .
\end{aligned}
$$

From the above, $\pi_{m}^{r m}>\pi_{m}^{n m}>\pi_{m}^{m m}$ and $\pi_{m}^{r c}>\pi_{m}^{n c}>\pi_{m}^{m c}$ J. Corollary 4

(1) Finding the first-order partial derivatives of the retailer's profit with respect to $s, \lambda_{m}$, and $\lambda_{r}$ yields

$$
\begin{aligned}
& \frac{\partial \pi_{r}^{n m^{*}}}{\partial s}=\frac{2 b k^{2} r^{2}(a-b c)^{2}(1-s)}{\left[4 b k(1-s)-r^{2}\right]^{3}>0,} \\
& \frac{\partial \pi_{r}^{m m^{*}}}{\partial s}=\frac{2 b k^{2} r^{2}(a-b c)^{2}(1-s)}{\left[2 b k\left(2-\lambda_{m}\right)(1-s)-r^{2}\right]^{3}}>0, \\
& \frac{\partial \pi_{r}^{m m^{*}}}{\partial \lambda_{m}}=\frac{4 b^{2} k^{3}(a-b c)^{2}(1-s)^{3}}{\left[2 b k\left(2-\lambda_{m}\right)(1-s)-r^{2}\right]^{3}}>0, \\
& \frac{\partial \pi_{r}^{m m^{*}}}{\partial \lambda_{m}}=\frac{4 b^{2} k^{3}(a-b c)^{2}(1-s)^{3}}{\left[2 b k\left(2-\lambda_{m}\right)(1-s)-r^{2}\right]^{3}}>0, \\
& \frac{\partial \pi_{r}^{m c^{*}}}{\partial_{\lambda}^{m}}=\frac{4 b^{2} k^{3}(1-s)^{2}[a-b c(1-s)]^{2}}{\left[2 b k(1-s)\left(2-\lambda_{m}\right)-r^{2}\right]^{3}}>0, \\
& \frac{\partial \pi_{r}^{r m^{*}}}{\partial \lambda_{r}}=\frac{2 b k^{2}(1-s)^{2}(a-b c)^{2}\left[\left(2-3 \lambda_{r}\right) r^{2}-4 b k\left(1-\lambda_{r}\right)(1-s)\right]}{\left[4 b k\left(1-\lambda_{r}\right)(1-s)-r^{2}\right]^{3}}<0 \\
& \frac{\partial \pi_{r}^{r c *}}{\partial \lambda_{r}}=\frac{2 b k^{2}[a-b c(1-s)]^{2}\left[\left(2-3 \lambda_{r}\right) r^{2}-4 b k\left(1-\lambda_{r}\right)(1-s)\right]}{\left.\left[4-\lambda_{r}\right)-r^{2}\right]^{3}}<0
\end{aligned}
$$

(2) Using the difference method to compare the retailer's profit separately: 


$$
\begin{aligned}
& \pi_{r}^{r m^{*}}-\pi_{r}^{m m^{*}}=\frac{b k^{2}(1-s)^{2}(a-b c)^{2}\left[4 b k(1-s)\left(1-\lambda_{r}\right)\left[b k(1-s)\left(\begin{array}{c}
\left(\lambda_{m}{ }^{2}-4 \lambda_{m}\right) \\
\left(1-3 \lambda_{r}\right)-8 \lambda_{r}
\end{array}\right)+r^{2}\left(\lambda_{m}\left(1-3 \lambda_{r}\right)+6 \lambda_{r}\right)\right]+\left(3 \lambda_{r}-4\right) \lambda_{r} r^{4}\right]}{\left[2 b k(1-s)\left(2-\lambda_{m}\right)-r^{2}\right]^{2}\left[4 b k(1-s)\left(1-\lambda_{r}\right)-r^{2}\right]^{2}}<0, \\
& \pi_{r}^{m m^{*}}-\pi_{r}^{n m^{*}}=\frac{4 b^{2} k^{3} \lambda_{m}(1-s)^{3}(a-b c)^{2}\left[b k(1-s)\left(4-\lambda_{m}\right)-r^{2}\right]}{\left[4 b k(1-s)-r^{2}\right]^{2}\left[2 b k(1-s)\left(2-\lambda_{m}\right)-r^{2}\right]^{2}}>0, \\
& \pi_{r}^{r m^{*}}-\pi_{r}^{n m^{*}}=\frac{b k^{2} \lambda_{r}(1-s)^{2}(a-b c)^{2}\left[8 b k\left(1-\lambda_{r}\right)(1-s)\left[3 r^{2}-4 b k(1-s)\right]+\left(3 \lambda_{r}-4\right) r^{4}\right]}{\left[4 b k(1-s)-r^{2}\right]^{2}\left[4 b k(1-s)\left(1-\lambda_{r}\right)-r^{2}\right]^{2}}, \\
& \pi_{r}^{r c *}-\pi_{r}^{m c^{*}}=\frac{b k^{2}(1-s)[a-b c(1-s)]^{2}\left[\begin{array}{c}
4 b^{2} k^{2}(1-s)^{2}\left(1-\lambda_{r}\right)\left[\lambda_{m}\left(1-4 \lambda_{m}\right)\left(1-3 \lambda_{r}\right)-8 \lambda_{r}\right] \\
+4 b k r^{2}(1-s)\left(1-\lambda_{r}\right)\left[\lambda_{m}\left(1-3 \lambda_{r}\right)+6 \lambda_{r}\right]+\left(3 \lambda_{r}^{2}-4 \lambda_{r}\right) r^{4}
\end{array}\right]}{\left[2 b k(1-s)\left(2-\lambda_{m}\right)-r^{2}\right]^{2}\left[4 b k(1-s)\left(1-\lambda_{r}\right)-r^{2}\right]^{2}}<0, \\
& \pi_{r}^{m c^{*}}-\pi_{r}^{n c *}=\frac{4 b^{2} k^{3} \lambda_{m}(1-s)^{2}[a-b c(1-s)]^{2}\left[4 b k(1-s)-b k \lambda_{m}(1-s)-r^{2}\right]}{\left[r^{2}-4 b k(1-s)\right]\left[2 b k(1-s)\left(2-\lambda_{m}\right)-r^{2}\right]}>0, \\
& \pi_{r}^{r c *}-\pi_{r}^{n c *}=\frac{b k^{2} \lambda_{r}(1-s)[a-b c(1-s)]^{2}\left[8 b k(1-s)\left(1-\lambda_{r}\right)\left(3 r^{2}-4 b k(1-s)\right)+\left(3 \lambda_{r}-4\right) r^{4}\right]}{\left[4 b k(1-s)-r^{2}\right]^{2}\left[4 b k(1-s)\left(1-\lambda_{r}\right)-r^{2}\right]^{2}} .
\end{aligned}
$$

From the above, when $k / r^{2}>3 / 4 b(1-s)$ or when $A<$ $k / r^{2}<3 / 4 b(1-s), 1>\lambda_{r}>8 b k(1-s)\left[3 r^{2}-4 b k(1-s)\right]-4 r^{4}$ / $8 b k(1-s)\left[3 r^{2}-4 b k(1-s)\right]-3 r^{4}, \pi_{r}^{m m}>\pi_{r}^{n m}>\pi_{r}^{r m}$, and $\pi_{r}^{m c}>\pi_{r}^{n c}>\pi_{r}^{r c}$; when $A<k / r^{2}<3 / 4 b(1-s)$ and $0<\lambda_{r}<$ $8 b k(1-s)\left[3 r^{2}-4 b k(1-s)\right]-4 r^{4} / 8 b k(1-s) \quad\left[3 r^{2}-4 b k\right.$ $(1-s)]-3 r^{4}, \pi_{r}^{m m}>\pi_{r}^{r m}>\pi_{r}^{n m}$ and $\pi_{r}^{m c}>\pi_{r}^{r c}>\pi_{r}^{n c}$.

\section{K. Corollary 5}

(1) Finding the first-order partial derivatives of the overall profit of the supply chain with respect to $s$, $\lambda_{m}$, and $\lambda_{r}$ yields

$$
\begin{aligned}
\frac{\partial \pi_{s c}^{n m^{*}}}{\partial s} & =\frac{k r^{2}(a-b c)^{2}\left[8 b k(1-s)-r^{2}\right]}{\left[4 b k(1-s)-r^{2}\right]^{3}}>0, \\
\frac{\partial \pi_{s c}^{m m^{*}}}{\partial s} & =\frac{k r^{2}(a-b c)^{2}\left[2 b k\left(4-3 \lambda_{m}\right)(1-s)-r^{2}\right]}{2\left[2 b k\left(2-\lambda_{m}\right)(1-s)-r^{2}\right]^{3}}>0,
\end{aligned}
$$

$$
\begin{aligned}
\frac{\partial \pi_{s c}^{r m^{*}}}{\partial s} & =\frac{k r^{2}(a-b c)^{2}\left[4 b k(1-s)\left(2-3 \lambda_{r}\right)\left(1-\lambda_{r}\right)-r^{2}\right]}{2\left[4 b k\left(1-\lambda_{r}\right)(1-s)-r^{2}\right]^{3}}>0, \\
\frac{\partial \pi_{s c}^{m m^{*}}}{\partial \lambda_{m}} & =\frac{4 b^{2} k^{3}(a-b c)^{2}(1-s)^{3}\left(1-\lambda_{m}\right)}{\left[2 b k\left(2-\lambda_{m}\right)(1-s)-r^{2}\right]^{3}}>0, \\
\frac{\partial \pi_{s c}^{m c^{*}}}{\partial_{\lambda}^{m}} & =\frac{4 b^{2} k^{3}(1-s)^{2}\left(1-\lambda_{m}\right)[a-b c(1-s)]^{2}}{\left[2 b k(1-s)\left(2-\lambda_{m}\right)-r^{2}\right]^{2}}>0, \\
\frac{\partial \pi_{s c}^{r m^{*}}}{\partial \lambda_{r}} & =\frac{2 b k^{2} r^{2}(a-b c)^{2}(1-s)^{2}\left(1-3 \lambda_{r}\right)}{\left[4 b k\left(1-\lambda_{r}\right)(1-s)-r^{2}\right]^{3}}>0, \\
\frac{\partial \pi_{s c}^{r c *}}{\partial \lambda_{r}} & =\frac{2 b k^{2} r^{2}(1-s)\left(1-3 \lambda_{r}\right)[a-b c(1-s)]^{2}}{\left[4 b k(1-s)\left(1-\lambda_{r}\right)-r^{2}\right]^{3}}>0 .
\end{aligned}
$$

(2) Using the difference method to compare the overall profit of the supply chain separately:

$$
\begin{aligned}
& \pi_{s c}^{r m *}-\pi_{s c}^{m m *}=\frac{b k^{2}(1-s)^{2}(a-b c)^{2}\left[4 b^{2} k^{2}(1-s)^{2}\left(1-\lambda_{r}\right)^{2}\left(3 \lambda_{m}^{2}-4 \lambda_{m}\right)+2 b k r^{2}(1-s)\left[4 \lambda_{r}\left(1-\lambda_{m}\right)+\lambda_{m}\left(2-\lambda_{m}\right)+2 \rho_{r}^{2}\left(3 \lambda_{m}-4\right)\right]+\left(3 \lambda_{r}^{2}-2 \lambda_{r}\right) r^{4}\right]}{\left[2 b k(1-s)\left(2-\lambda_{m}\right)-r^{2}\right]^{2}\left[4 b k(1-s)\left(1-\lambda_{r}\right)-r^{2}\right]^{2}}<0, \\
& \pi_{s c}^{r m *}-\pi_{s c}^{n m *}=\frac{b k^{2} r^{2} \lambda_{r}(1-s)^{2}(a-b c)^{2}\left[8 b k(1-s)\left(1-2 \lambda_{r}\right)+\left(3 \lambda_{r}-2\right) r^{2}\right]}{\left[4 b k(1-s)-r^{2}\right]^{2}\left[4 b k(1-s)\left(1-\lambda_{r}\right)-r^{2}\right]^{2}}>0, \\
& \pi_{s c}^{m m *}-\pi_{s c}^{n m *}=\frac{2 b^{2} k^{3} \lambda_{m}(1-s)^{3}(a-b c)^{2}\left[2 b k(1-s)\left(4-3 \lambda_{m}\right)+\left(\lambda_{m}-2\right) r^{2}\right]}{\left[r^{2}-4 b k(1-s)\right]^{2}\left[2 b k(1-s)\left(2-\lambda_{m}\right)-r^{2}\right]^{2}}>0, \\
& \pi_{s c}^{r c *}-\pi_{s c}^{m c *}=\frac{b k^{2}(1-s)[a-b c(1-s)]^{2}\left[4 b^{2} k^{2}(1-s)^{2}\left(1-\lambda_{r}\right)^{2}\left(3 \lambda_{m}^{2}-4 \lambda_{m}\right)+2 b k r^{2}(1-s)\left[4 \lambda_{r}\left(1-\lambda_{m}\right)+\lambda_{m}\left(2-\lambda_{m}\right)+2 \lambda_{r}^{2}\left(3 \lambda_{m}-4\right)\right]+\left(3 \lambda_{r}^{2}-2 \lambda_{r}\right) r^{4}\right]}{\left[2 b k(1-s)\left(2-\lambda_{m}\right)-r^{2}\right]^{2}\left[4 b k(1-s)\left(1-\lambda_{r}\right)-r^{2}\right]^{2}}<0,
\end{aligned}
$$




$$
\begin{aligned}
\pi_{s c}^{r c *}-\pi_{s c}^{n c *} & =\frac{b k^{2} r^{2} \lambda_{r}(1-s)[a-b c(1-s)]^{2}\left[8 b k(1-s)\left(1-2 \lambda_{r}\right)+\left(3 \lambda_{r}-2\right) r^{2}\right]}{\left[4 b k(1-s)-r^{2}\right]^{2}\left[4 b k(1-s)\left(1-\lambda_{r}\right)-r^{2}\right]^{2}}>0, \\
\pi_{s c}^{m c *}-\pi_{s c}^{n c *} & =\frac{2 b^{2} k^{3} \lambda_{m}(1-s)^{2}[a-b c(1-s)]^{2}\left[2 b k(1-s)\left(4-3 \lambda_{m}\right)+\left(\lambda_{m}-2\right) r^{2}\right]}{\left[r^{2}-4 b k(1-s)\right]^{2}\left[2 b k(1-s)\left(2-\lambda_{m}\right)-r^{2}\right]^{2}}>0 .
\end{aligned}
$$

From the above, $\pi_{s c}^{m m}>\pi_{s c}^{r m}>\pi_{s c}^{n m}$ and $\pi_{s c}^{m c}>\pi_{s c}^{r c}>\pi_{s c}^{n c}$.

\section{Corollary 6}

Using the difference method to horizontally compare the equilibrium results, we can obtain the following:

(1) Completely self-interested:

$$
\begin{aligned}
p^{n m^{*}}-p^{n c *} & =\frac{3 a k s}{r^{2}-4 b k(1-s)}<0, \\
w^{n m^{*}}-w^{n c *} & =\frac{2 a k s}{r^{2}-4 b k(1-s)}<0, \\
e^{n m^{*}}-e^{n c *} & =\frac{b c r s}{4 b k(1-s)-r^{2}}<0,
\end{aligned}
$$

$$
\begin{aligned}
& \pi_{m}^{n m^{*}}-\pi_{m}^{n c *}=\frac{k s\left[a^{2}-b^{2} c^{2}(1-s)\right]}{2\left[r^{2}-4 b k(1-s)\right]}<0, \\
& \pi_{r}^{n m^{*}}-\pi_{r}^{n c *}=\frac{b k^{2} s(s-1)\left[a^{2}-b^{2} c^{2}(1-s)\right]}{\left[r^{2}-4 b k(1-s)\right]^{2}}<0,
\end{aligned}
$$$$
\pi_{s c}^{n m^{*}}-\pi_{s c}^{n c *}=\frac{k s\left[a^{2}-b^{2} c^{2}(1-s)\right]\left[r^{2}-6 b k(1-s)\right]}{2\left[r^{2}-4 b k(1-s)\right]^{2}}<0 .
$$

(2) The manufacturer's altruistic:

$$
\begin{aligned}
p^{m m^{*}}-p^{m c^{*}} & =\frac{a k s\left(2 \lambda_{m}-3\right)}{2 b k(1-s)\left(2-\lambda_{m}\right)-r^{2}}<0 \\
w^{m m^{*}}-w^{m c^{*}} & =\frac{2 a k s\left(\lambda_{m}-1\right)}{2 b k(1-s)\left(2-\lambda_{m}\right)-r^{2}}<0 \\
e^{m m^{*}}-e^{m c^{*}} & =\frac{-b c r s}{2 b k(1-s)\left(2-\lambda_{m}\right)-r^{2}}<0 \\
\pi_{m}^{m m^{*}}-\pi_{m}^{m c^{*}} & =\frac{-k s\left[a^{2}-b^{2} c^{2}(1-s)\right]\left[4 b k f g(1-s)\left(1-\lambda_{m}\right)-r^{2}\right]}{2\left[2 b k(1-s)\left(2-\lambda_{m}\right)-r^{2}\right]^{2}}<0 \\
\pi_{r}^{m m^{*}}-\pi_{r}^{m c^{*}} & =\frac{b k^{2} s(1-s)\left[a^{2}-b^{2} c^{2}(1-s)\right]}{\left[2 b k(1-s)\left(2-\lambda_{m}\right)-r^{2}\right]^{2}}<0, \\
\pi_{s c}^{m m^{*}}-\pi_{s c}^{m c^{*}} & =\frac{-k s\left[a^{2}-b^{2} c^{2}(1-s)\right]\left[2 b k(1-s)\left(3-2 \lambda_{m}\right)-r^{2}\right]}{2\left[2 b k(1-s)\left(2-\lambda_{m}\right)-r^{2}\right]^{2}}<0 .
\end{aligned}
$$


(3) The retailer's altruistic:

$$
\begin{aligned}
p^{r m^{*}}-p^{r c *} & =\frac{3 a k s\left(\lambda_{r}-1\right)}{4 b k(1-s)\left(1-\lambda_{r}\right)-r^{2}}<0, \\
w^{r m^{*}}-w^{r c *} & =\frac{-2 a k s}{4 b k(1-s)\left(1-\lambda_{r}\right)-r^{2}}<0, \\
e^{r m^{*}}-e^{r c *} & =\frac{-b c r s}{4 b k(1-s)\left(1-\lambda_{r}\right)-r^{2}}<0, \\
\pi_{m}^{r m^{*}}-\pi_{m}^{r c *} & =\frac{-k s\left[a^{2}-b^{2} c^{2}(1-s)\right]}{2\left[4 b k(1-s)\left(1-\lambda_{r}\right)-r^{2}\right]}<0, \\
\pi_{r}^{r m^{*}}-\pi_{r}^{r c *} & =\frac{b k^{2} s(s-1)\left(1-\lambda_{r}\right)\left(1-3 \lambda_{r}\right)\left[a^{2}-b^{2} c^{2}(1-s)\right]}{2\left[4 b k(1-s)\left(1-\lambda_{r}\right)-r^{2}\right]}<0, \\
\pi_{s c}^{r m^{*}}-\pi_{s c}^{r c *} & =\frac{k s\left[r^{2}-6 b k(1-s)\left(1-\lambda_{r}\right)^{2}\right]\left[a^{2}-b^{2} c^{2}(1-s)\right]}{2\left[4 b k(1-s)\left(1-\lambda_{r}\right)-r^{2}\right]^{2}}<0 .
\end{aligned}
$$

Proof completed.

\section{Data Availability}

The data used to support the findings of this study are available from the corresponding author upon request.

\section{Conflicts of Interest}

The authors declare no conflicts of interest.

\section{Acknowledgments}

This is research was supported by the National Natural Science Foundation of China (Grant no.72074110 and 71771055), Anhui Planning Office of Philosophy and Social Science Project (Grant no. AHSKQ2020D49), Research Project Innovation and Development of Anhui (Grant no. 2020CX057), Talent Project of Fuyang Normal University (Grant nos. rcxm202012, 2020KYQD0008), Key Project of Humanities and Social Sciences of Anhui (Grant no. SK2021A0393), and Postgraduate Project of Fuyang Normal University (Grant no.2021SKY19).

\section{References}

[1] W. W. Gong, J. Shen, and J. X. Chen, Dynamic Strategy of Dual-Channel Green Product Supply Chain under Risk Appetite[J/OL], pp. 1-22, Computer Integrated Manufacturing System, 2021, http://kns.cnki.net/kcms/detail/11.5946.tp.2021 0531.1543.028.htm.

[2] S. Qu, Y. Zhou, Y. Zhang, M. I. M. Wahab, G. Zhang, and Y. Ye, "Optimal strategy for a green supply chain considering shipping policy and default risk," Computers \& Industrial Engineering, vol. 131, pp. 172-186, 2019.

[3] Starbucks, Starbucks to Eliminate Plastic Straws Globally by 2020, https://stories.star-bucks.com/press/2018/starbucks-toeliminate-plastic-straws-globallyby-2020/, 2019.
[4] Informa, Volvo Targets 25\% Sustainable Plastic in Cars by 2025, https://www.plastics-today.com/automotive-andmobility/volvo-targets-25-sustainable-plasticcars-2025, 2018.

[5] Y. J. Cai and T. M. Choi, "A United Nations' Sustainable Deveiopment Goals perspective for sustainable textile and apparel supply chain management," Transportation Research Part E: Log. Transp. Rev.vol. 141, Article ID 102010, 2020.

[6] S. Samad and M. Nilashi, "Green Supply Chain Management practices and impact on firm performance: the moderating effect of collaborative capability," Technology in Society, vol. 67, pp. 101-766, 2021.

[7] L. Rong and M. Xu, "Impact of altruistic preference and government subsidy on the multinational green supply chain under dynamic tariff. Environment," Development and Sustainability, pp. 1-31, 2021.

[8] H. Zhang, L. Shen, S. Zhong, and A. Elshkaki, "Economic structure transformation and low-carbon development in energy-rich cities: the case of the contiguous area of Shanxi and Shaanxi provinces, and inner Mongolia autonomous region of China," Sustainability, vol. 12, no. 5, p. 1875, 2020.

[9] Y. Wang, Z. Yu, M. Jin, and J. Mao, "Decisions and coordination of retailer-led low-carbon supply chain under altruistic preference," European Journal of Operational Research, vol. 293, no. 3, pp. 910-925, 2021.

[10] S. Rezaei and R. Maihami, "Optimizing the sustainable decisions in a multi-echelon closed-loop supply chain of the manufacturing/remanufacturing products with a competitive environment," Environment, Development and Sustainability, vol. 22, no. 7, pp. 6445-6471, 2019.

[11] S. B. Peterson and J. Michalek, "Cost-effectiveness of plug in hybrid electric vehicle battery capacity and charging infrastructure investment for reducing US gasoline consumption," Energy Policy, vol. 52, pp. 429-438, 2013.

[12] Q. Xia, B. D. Zhi, and X. J. Wang, "The role of crossShareholding in the green supply chain: green contribution, power structure and coordination," International Journal of Production Economics, vol. 234, Article ID 108037, 2021.

[13] Y. Wang, Z. Yu, and L. Shen, "Study on the decision-making and coordination of an e-commerce supply chain with manufacturer fairness concerns," International Journal of Production Research, vol. 57, no. 9, pp. 2788-2808, 2019.

[14] Y. Y. Wang, R. J. Fan, L. Shen, and W. Miller, "Recycling decisions of low -carbone -commerceclosed -loopsupply chain under government subsidy mechanism and altruistic preference," Journal of Cleaner Production, vol. 259, Article ID 120883, 2020.

[15] A. Gamba, "Learning and evolution of altruistic preferences in the centipede game," Journal of Economic Behavior \& Organization, vol. 85, pp. 112-117, 2013.

[16] Yuyin, "The effect of governmental policies of carbon taxes and energy-saving subsidies on enterprise decisions in a twoechelon supply chain," Journal of Cleaner Production, vol. 181, pp. 675-691, 2018.

[17] J.-B. Sheu and Y. J. Chen, "Impact of government financial intervention on competition among green supply chains," International Journal of Production Economics, vol. 138, no. 1, pp. 201-213, 2012.

[18] S. Huang, Z.-P. Fan, and N. Wang, "Green subsidy modes and pricing strategy in a capital- constrained supply chain," Transportation Research Part E: Logistics and Transportation Review, vol. 136, pp. 101-885, 2020.

[19] H. Khosroshahi, S. Dimitrov, and S. R. Hejazi, "Pricing, greening, and transparency decisions considering the impact 
of government subsidies and CSR behavior in supply chain decisions," Journal of Retailing and Consumer Services, vol. 60, pp. 102-485, 2021.

[20] R. Fan, J. Lin, and K. Zhu, "Study of game models and the complex dynamics of a low-carbon supply chain with an altruistic retailer under consumers' low-carbon preference," Physica A, vol. 528, pp. 121-460, 2019.

[21] W. Liu, X. Yan, W. Wei, D. Xie, and D. Wang, "Altruistic preference for investment decisions in the logistics service supply chain," European Journal of Industrial Engineering, vol. 12 , no. 4 , pp. $598-635,2018$ a.

[22] P. J. Subrata and S. K. Mondal, "Exploring a two-layer green supply chain game theoretic model with credit linked demand and mark-up under revenue sharing contract," Journal of Cleaner Production, vol. 250, Article ID 119491, 2019.

[23] J. Wang, Q. Wan, and M. Z. Yu, "Green supply chain network design considering chain-to-chain competition on price and carbon emission," Computers \& Industrial Engineering, vol. 145, Article ID 106503, 2020.

[24] J. Zhang, Z. Y. Wang, and H. J. Zhao, “The impact of consumer subsidy on green technology innovations for vehicles and environmental impact," International Journal of Environmental Research and Public Health, vol. 17, p. 7518, 2020.

[25] J. Jie, B. Li, N. Zhang, and J. Su, "Decision-making and coordination of green closed-loop supply chain with fairness concern," Journal of Cleaner Production, vol. 298, Article ID 126779, 2021.

[26] H. Jafar, K. Govindan, and B. Zahra, "Balancing price and green quality in presence of consumer environmental awareness: a green supply chain coordination approach," International Journal of Production Research, vol. 59, pp. 1957-1975, 2021.

[27] Z. Mu, Y. Zheng, and H. Sun, "Cooperative green technology innovation of an E-commerce sales channel in a two-stage supply chain," Sustainability, vol. 13, no. 13, p. $7499,2021$.

[28] S. An, B. Li, D. Song, and X. Chen, "Green credit financing versus trade credit financing in a supply chain with carbon emission limits," European Journal of Operational Research, vol. 292, no. 1, pp. 125-142, 2021.

[29] J. Y. Wei and C. X. Wang, "Improving interaction mechanism of carbon reduction technology innovation between supply chain enterprises and government by means of differential game," Journal of Cleaner Production, vol. 296, Article ID 126578, 2021.

[30] Z. Liu, Z. Xiao-Xue, Li Deng-Feng, L. Chen-Nan, and S. JiuhBiing, "A novel cooperative game-based method to coordinate a sustainable supply chain under psychological uncertainty in fairness concerns," Transportation Research Part E: Logistics and Transportation Review, vol. 147, Article ID 102237, 2021.

[31] Z. Liu, Li W. Kevin, J. Tang, B.-G. Gong, and J. Huang, "Optimal operations of a closed-loop supply chain under a dual regulation," International Journal of Production Economics, vol. 233, Article ID 107991, 2021.

[32] Q. Qin, M. Jiang, and J. Xie, "Game analysis of environmental cost allocation in green supply chain under fairness preference," Energy Reports, vol. 7, pp. 6014-6022, 2021.

[33] J. Y. Yu, C. S. Tang, and Z. J. Shen, "Improving consumer welfare and manufacturer profit via government subsidy programs: subsidizing consumers or manufacturers?" Manufacturing \& Service Operations Management, vol. 20, no. 4, pp. 752-766, 2018.

[34] Q. C. Meng, Y. T. Wang, Z. Zhang, and Y. Y. He, "Supply chain green innovation subsidy strategy considering consumer heterogeneity," Journal of Cleaner Production, vol. 281, Article ID 125199, 2020.

[35] C. Fang and T. Ma, "Stylized agent-based modeling on linking emission trading systems and its implications for China's practice," Energy Economics, vol. 92, Article ID 104916, 2020.

[36] C. Su, X. J. Liu, and W. Y. Du, "Green supply chain decisions considering consumers' low-carbon awareness under different government subsidies," Sustainability, vol. 12, p. 2281, 2020.

[37] B. Lin and Z. Jia, "Is emission trading scheme an opportunity for renewable energy in China? A perspective of ETS revenue redistributions," Applied Energy, vol. 263, Article ID 114605, 2020.

[38] J. S. Bian, G. Q. Zhang, and G. H. Zhou, "Manufacturer vs. consumer subsidy with green technology investment and environmental concern," European Journal of Operational Research, vol. 287, pp. 832-843, 2020.

[39] Q. F. Meng, M. W. Li, W. Y. Liu, Z. Li, and J. Zhang, "Pricing policies ofdual -channelgreen supply chain :Considering government subsidies and consumers 'dual preferences," Sustainable Production and Consumption, vol. 26, pp. 10211030, 2021.

[40] R. Yang, W. S. Tang, and J. X. Zhang, "Technology improvement strategy for green products under competition: the role of government subsidy," European Journal of Operational Research, vol. 289, pp. 553-568, 2021.

[41] B. Li, H. R. Wang, and W. Zheng, "Who will take on green product development in supply chains? Manufacturer or retailer," Journal of Cleaner Production, vol. 314, Article ID 128000, 2021.

[42] C. F. Li, Q. L. Liu, P. Zhou, and H. J. Huang, "Optimal innovation investment :the role ofsubsidy schemes and supply chain channel power structure," Computers \& Industrial Engineering, vol. 157, Article ID 107291, 2021.

[43] J. Yu, X. Shi, D. Guo, and L. Yang, "Economic policy uncertainty (EPU) and firm carbon emissions: evidence using a China provincial EPU index," Energy Economics, vol. 94, Article ID 105071, 2021.

[44] Y. Y. Wang, Z. Q. Yu, L. Shen, and W. Q. Dong, "E-commerce supply chain models under altruistic preference," Mathematics, vol. 9, p. 632, 2021.

[45] H. Huang, J. Zhang, R. Xuan, and X. Zhou, "Greenness and pricing decisions of cooperative supply chains considering altruistic preferences," International Journal of Environmental Research and Public Health, vol. 16, p. 51, 2019.

[46] Y. Y. Wang, R. R. Fan, L. Shen, and W. Miller, "Recycling decisions of low-carbon e-commerce closed-loop supply chain under government subsidy mechanism and altruistic preference," Journal of Cleaner Production, vol. 259, Article ID 120883, 2020.

[47] Y. Y. Wang, Z. Q. Yu, L. Shen, and W. Q. Dong, "Impacts of altruistic preference and reward-penalty mechanism on decisions of E-commerce closed-loop supply chain," Journal of Cleaner Production, vol. 315, Article ID 128132, 2021.

[48] K. Kang, S. Gao, T. Gao, and J. Zhang, "Pricing and financing strategies for a green supply chain with a risk-averse supplier," IEEE Access, vol. 9, pp. 9250-9261, 2021.

[49] S. Swami and J. Shah, "Channel coordination in green supply chain management," The Journal of the Operational Research Society, vol. 64, pp. 336-351, 2013.

[50] T. J. Yang and J. G. Tian, "Supply chain pricing and green innovation strategies under different channel power structures," Soft Science, vol. 33, pp. 127-132, 2019. 
[51] The Interview about Suning in, http://m.jc001.cn/news/ 480459.html, 2010.

[52] C. Zhang, Y. Liu, and G. H. Han, "Two-stage pricing strategies of a dual-channel supply chain considering public green preference," Computers \& Industrial Engineering, vol. 151, Article ID 106988, 2021.

[53] Q. Xia, B. D. Zhi, and X. J. Wang, "The role of crossshareholding in the green supply chain: green Contribution,Power structure and coordination," International Journal of Production Economics, vol. 234, Article ID 108037, 2021.

[54] Y. N. Li, T. Yang, F. Ye, and J. J. Song, "The choice of the government green subsidy scheme: innovation subsidy vs. product subsidy," International Journal of Production Research, vol. 58, pp. 4932-4946, 2020.

[55] Z. M. Liu, L. Xu, X. R. Peng, and S. Lee, "Green or nongreen innovation ?Different strategic preferences among subsidized enterprises with different ownership types," Journal of Cleaner Production, vol. 245, Article ID 118786, 2019.

[56] Z. M. Li, Y. C. Pan, W. . Yang, J. H. . Ma, and M. Zhou, "Effects ofgovernment subsidies ongreen technology investment and green marketing coordination ofsupply chain under Cap -and-trademechanism," Energy Economics, vol. 101, Article ID 105426, 2021.

[57] M. Peng, Y. M. Gong, and M. Z. Jin, "Quality efforts in medical supply chains considering patient benefits," European Journal of Operational Research, vol. 279, pp. 795-807, 2019.

[58] Q. R. Lu and M. Z. Xu, "Impact of altruistic preference and government subsidy on the multinational green supply chain under dynamic tariff," Environment, Development and Sustainability, 2021. 